NBER WORKING PAPER SERIES

\title{
SUBSIDIZING LOW- AND MIDDLE-INCOME ADOPTION OF ELECTRIC VEHICLES: QUASI-EXPERIMENTAL EVIDENCE FROM CALIFORNIA
}

\author{
Erich Muehlegger \\ David S. Rapson \\ Working Paper 25359 \\ http://www.nber.org/papers/w25359 \\ NATIONAL BUREAU OF ECONOMIC RESEARCH \\ 1050 Massachusetts Avenue \\ Cambridge, MA 02138 \\ December 2018, Revised January 2021
}

We gratefully acknowledge research funding from the State of California Public Transportation Account and the Road Repair and Accountability Act of 2017 (Senate Bill 1) via the University of California Institute of Transportation Studies. We thank Tom Knox at Valley Clean Air Now and Mei Wang at South Coast Air Quality Management District for sharing their expertise on the pilot programs in San Joaquin Valley and South Coast, respectively; the California Air Resources Board for their support of this project and for funding for acquisition of some of the data used in this analysis; Jim Archsmith, Ben Dawson, Jack Gregory, Tyler Hoppenfeld and Shotaro Nakamura for excellent research assistance; and many seminar participants. The views expressed herein are those of the authors and do not necessarily reflect the views of the California Air Resources Board or the National Bureau of Economic Research.

NBER working papers are circulated for discussion and comment purposes. They have not been peer-reviewed or been subject to the review by the NBER Board of Directors that accompanies official NBER publications.

(C) 2018 by Erich Muehlegger and David S. Rapson. All rights reserved. Short sections of text, not to exceed two paragraphs, may be quoted without explicit permission provided that full credit, including $\odot$ notice, is given to the source. 
Subsidizing Low- and Middle-Income Adoption of Electric Vehicles: Quasi-Experimental

Evidence from California

Erich Muehlegger and David S. Rapson

NBER Working Paper No. 25359

December 2018, Revised January 2021

JEL No. H22,H23,H71,L62,Q48,Q55,Q58,R48

\begin{abstract}
Little is known about electric vehicle (EV) demand by low- and middle-income households. In this paper, we exploit a policy that provides exogenous variation in large EV subsidies targeted at the mass market in California. Using transaction-level data, we estimate three important policy parameters: the rate of subsidy pass-through, the impact of the subsidy on EV adoption, and the elasticity of demand for EVs among low- and middle-income households. Demand for EVs in our sample is price-elastic (-3.3) and pass-through to buyers is indistinguishable from 100 percent. We use these estimates to calculate that the expected subsidy bill required for California to reach its goal of 1.5 million EVs by 2025 is likely to exceed $\$ 12-18$ billion.
\end{abstract}

Erich Muehlegger

Department of Economics

University of California, Davis

One Shields Avenue

Davis, CA 95616

and NBER

emuehlegger@ucdavis.edu

David S. Rapson

Department of Economics

University of California, Davis

One Shields Avenue

Davis, CA 95616

dsrapson@ucdavis.edu

A data appendix is available at http://www.nber.org/data-appendix/w25359 


\section{Introduction}

Electrification of the vehicle fleet is seen by many policy-makers as central to reducing greenhouse gas emissions, local air pollution and dependence on oil. Local, state and national governments have set ambitious targets for widespread adoption of electric vehicles (EVs) or phasing out internal combustion engines (ICEs) entirely. In recent years, countries announcing plans to ban ICEs sales include France and UK (by 2040), Norway (by 2025), India (by 2030), and China. Germany has announced plans to put 1 million electric vehicles on the road by 2020. In the U.S., California is leading the charge. In 2013, Governor Brown issued an executive order to put 1.5 million so-called "Zero Emissions Vehicles" (ZEVs) on the road by 2025 (and 5 million by 2030) as part of a goal to reduce transportation emissions by 50 percent by 2030. To spur adoption, policy-makers pair these targets with generous subsidy programs. The cost of these programs is considerable and presents stark tradeoffs for public funds. As of mid2020, California has spent nearly $\$ 900$ million on the state-wide vehicle subsidies, and recent proposals suggested allocating another $\$ 3$ billion in the state. Federal incentives for electric vehicles total up to $\$ 1.5$ billion per manufacturer.

Although a long literature estimates the impact of incentives for hybrid, electric or alternativefuel vehicles, ${ }^{1}$ research on past programs may not provide a good guide as to the impact or fiscal costs of meeting these ambitious targets for two reasons. First, past incentives for alternative vehicles rarely offer the quasi-experimental variation necessary for clean causal identification. In virtually all cases, the decision to offer an incentive is endogenously determined. States with populations predisposed to purchase EVs are more likely to offer incentives, confounding estimation of the causal impact of incentives on vehicle adoption. Second, and equally important, the ambitious targets described above require widespread adoption of electric vehicles. ${ }^{2}$ Yet, past incentive programs typically offered a blanket subsidy to all vehicle buyers, the take-up of which is strongly correlated with income. As Borenstein and Davis (2016) documents, high income households were significantly more likely adopt EVs and claimed the vast majority of federal vehicle incentives, and the income distribution of subsidy recipients has not changed over time. ${ }^{3}$ As such, elasticities derived from early adoption may be less relevant for assessing the impacts or costs of policies or targets that require widespread adoption of alternative

\footnotetext{
${ }^{1}$ e.g., Chandra et al. (2010), Gallagher and Muehlegger (2011), Beresteanu and Li (2011), Clinton and Steinberg (2017) study effects on adoption, Sallee (2011), Gulati et al. (2017) study pass-through and recent papers, including Li et al. (2017), Li (2017), Springel (2017), study network effects of charging stations.

${ }^{2}$ Mary Nichols, Chair of the California Air Resource Board, noted in Jan 2018 that that the 2030 market share of EVs in California would have to be approximately $40 \%$ to meet the 5 million by 2030 goal (Los Angeles Times).

${ }^{3}$ https://energyathaas.wordpress.com/2019/05/13/an-electric-vehicle-in-every-driveway/
} 
fuel vehicles. Given the imminence of major policy decisions relating to these targets and transportation emissions reductions in general, there is an urgent need to better understand demand for EVs in the mass market.

In this paper, we study the impacts of the Enhanced Fleet Modernization Program ("EFMP"), a California retire-and-replace subsidy program for EV purchases that addresses both of the challenges above. The design of the EFMP provides clean quasi-experimental variation in the availability of the subsidy to some buyers and not others, allowing for a transparent treatmentto-control comparison. Furthermore, subsidy eligibility is means-tested, directing subsidies specifically towards low- and middle-income buyers. This allows us the opportunity to estimate the elasticity of demand for EVs for a sub-population that has not, historically, adopted electric vehicles, but will be an important market for meeting ambitious policy targets.

We analyze the universe of electric vehicle sales in California, a state that accounts for 40 percent of EV purchases in the United States and 10 percent of purchases worldwide. Using difference-in-difference, matched diff-in-diff and triple-differenced models that exploit geographic, temporal and subsidy-exposure variation, we retrieve estimates of three policy-relevant parameters: the rate of subsidy pass-through for the program, the impact on EV adoption and the elasticity of demand for EVs among low- to middle-income buyers. Low- and middleincome buyers capture the majority of the subsidy, consistent with the intentions of program designers. Each of these is essential for understanding the effectiveness of public expenditures on demand-side EV subsidies. In all of our specifications, the rate of subsidy pass-through is close to 100 percent, and in no specification can we reject full pass-through. In addition, we find that low- and middle-income buyers are relatively responsive to the subsidies. In each of our specifications, the estimated demand elasticity is within a tight range between -3.2 and -3.4, implying that a subsidy that decreases the buy-price of an EV by 10 percent will increase demand for that EV by 32-34 percent. While this may seem like a large effect at first glance, the small baseline quantity implies that even a large elasticity translates into a modest number of additional EVs.

Together, and under assumptions about generalizability, these objects can be combined to estimate the magnitude of subsidy funds that would be required to achieve a policy goal along the lines of "put 1.5 million ZEVs on the road". Under optimistic estimates of the baseline (nosubsidy) rate of EV growth in California going forward, we place the likely required subsidy bill at no less than $\$ 12-\$ 18$ billion for a program that would subsidize new EVs. ${ }^{4}$ The mag-

\footnotetext{
${ }^{4}$ We view this as a lower bound as a result of having made conservative assumptions throughout that would, if anything, lead this number to be too low. Moreover, our estimates of demand elasticity are large relative to the literature,
} 
nitude of the estimated subsidy bill is large, and may compel California regulators to explore policy alternatives. A mandate or a "feebate" would shift the burden of the policy away from California taxpayers, although these have very different implications for economic efficiency. The burden on California taxpayers will also be affected by a continuation or cancelation of the existing federal EV tax credit that is presently being reconsidered.

While we are encouraged to offer an estimate of the EV demand elasticity in California that is retrieved using quasi-experimental variation, context is required for those who wish to extrapolate these results. The suitability of these estimates for general use as demand elasticities may differ by setting (construct validity). Subsidy eligibility under the EFMP is linked to having a car to scrap, and is also driven by targeted marketing efforts by program administrators, particularly in one of the pilot regions. Moreover, the program does not exist in isolation, which is a feature common to all EV elasticity estimates in the literature to date. The presence of large federal and state subsidies for new EVs affects the interpretation of results since many of the new EVs purchased under a given subsidy program (in our case EFMP) were eligible for other state-wide or federal EV subsidies as well. Moreover, the ZEV Mandate - a policy requiring manufacturers to sell a certain proportion of EVs in California and nine other participating states - implicitly subsidizes manufacturers who sell EVs. While our empirical design nets out effects of statewide and federal demand-side subsidies as well as supply-side programs, the extent to which our elasticity estimates (which reflect marginal subsidy changes) apply to ranges of prices on the inframargin is an open question.

Notwithstanding these caveats, this paper makes several new contributions to the state of knowledge about the market for EVs. First, we provide (to our knowledge) the first estimates of the EV demand elasticity that are supported by a treatment-versus-control empirical design that allows key identifying assumptions to be tested directly. Second, ours is (again, to our knowledge) the first paper to examine EV adoption amongst low- and middle-income households that form the bulk of the market and will be central to meeting ambitious EV targets. Third, our estimates of subsidy pass-through contribute to the literature on the incidence of vehicle incentives. Fourth, we use our elasticity and incidence estimates to offer the first estimate of the range of subsidies required to meet California's 2025 EV adoption targets grounded by causal identification. This contributes to an important contemporary policy debate that is likely to be repeated in jurisdictions across the globe in coming years.

and the subsidy bill is inversely related to the demand elasticity. 


\section{Institutional Details and Data}

The Enhanced Fleet Modernization Program is a vehicle incentive program in California that provides subsidies to low- and middle-income households to scrap old vehicles for newer (although in some cases, still used), cleaner and more fuel efficient vehicles. ${ }^{5}$ The EFMP was initially designed as a retire-and-replace program along the lines of cash-for-clunkers. ${ }^{6}$ In April 2015, the California Air Resources Board ("ARB") redesigned the program to combine features of a retire-and-replace program with an incentive program for the purchase of high fuel economy vehicles and EVs, targeting low- and middle-income consumers in disadvantaged communities ("DACs"). ${ }^{7}$ The redesigned program, the focus of this paper, was launched as a pilot in July 2015 in two Air Quality Management Districts ("AQMDs"): the San Joaquin Valley Air Pollution Control District and the South Coast Air Quality Management District. Over the first two years, the pilot program received $\$ 72$ million in state funding with the expectation to expand the program to other metro areas. ${ }^{8}$

\subsection{Subsidy eligibility and generosity}

The pilot program is restricted to participants residing in the two AQMDs and retiring a qualifying vehicle. ${ }^{9}$ Within the AQMD, the EFMP targets: (a) households living in or near "disadvantaged" communities and (b) low- and middle-income households at or below $400 \%$ of the federal poverty line. ${ }^{10}$

To participate in the program, households must reside in a designated "disadvantaged community". The disadvantage designation is determined by the California Enviornmental Protection Agency ("CalEPA"). At the census-tract-level, CalEPA calculates a CalEnviroScreen ("CES") score that aggregates traditional measures of socio-economic disadvantage (e.g., poverty and unemployment), measures of pollution exposure (e.g., ambient air pollution levels and the presence of clean-up and solid waste sites) and sensitivity to pollution (e.g., child

\footnotetext{
${ }^{5}$ EFMP is a distinct program from the Clean Vehicle Rebate Program ("CVRP"), the main consumer-facing alternative vehicle incentive program in California that is available state-wide and, until recently, was available to all private buyers of qualified vehicles.

${ }^{6}$ See Mian and Sufi (n.d.), Li et al. (2013) for analyses examining the effects of the federal Cash-for-Clunkers program.

${ }^{7}$ https: / / www.arb.ca.gov/msprog/aqip/efmp/finalregulationorder2014.pdf

${ }^{8}$ ARB is in negotiation with three new AQMDs (Bay Area AQMD, Sac Metro AQMD, San Diego AQMD) to expand the program.(see. e.g., https://www.arb.ca.gov/board/books/2017/062217/17-6-1pres.pdf). If expanded, ninety percent of "disadvantaged communities" (described further below) in California will be covered by the EFMP.

${ }^{9}$ Vehicles must be: (1) a light-duty vehicle, (2) registered and insured for the two previous years, (3) with relatively high emissions, defined by the AQMD.

${ }^{10}$ Appendix figure A1 illustrates a flowchart for eligiblity.
} 
and elderly share of the population) at the census-tract level. ${ }^{11}$ CalEPA classifies all census tracts with CES score in the top quartile of the state-wide CES distribution as a disadvantaged census tract. To qualify for the EFMP program, a household must reside in a "disadvantaged zip code", a zip code that (wholly or partially) contains a disadvantaged census tract. We refer to these "disadvantaged zip codes" as disadvantaged communities ("DACs").

Within these DACs, the program is means-tested with lower income households eligible for more generous incentives. Households below the $225 \%$ of the FPL are eligible for the most generous incentives: $\$ 5,000$. As household income rises, subsidy generosity declines until a household is no longer eligible for the program, above $400 \%$ of the federal poverty line. Table 1 lists the subsidies that we study in this paper, which are available for program participants who trade in their vehicle for an electric vehicle. ${ }^{12}$

Figure 1 maps zip code boundaries for the Southern two-thirds of California. Regions in grey are the San Joaquin Valley and South Coast AQMDs, the two AQMDs that piloted the EFMP over our study period. The zip codes in pink are those that contain a disadvantaged census tracts. Thus, means-tested households in zip codes that are both grey and pink would be eligible for the subsidy. Outside of the grey and pink boundaries of the two participating AQMDs and disadvantage zip codes, households would be ineligible.

Figure 2 plots the histogram the maximum CES score within a zip code for participating AQMDs (right panel) and non-participating AQMDs (left panel). The vertical red line in each plot marks the 75th percentile of state-wide CES score Zip codes to the right of the red line would be classified as disadvantaged communities by the rules of the program. Roughly 80 percent of the population of the San Joaquin Valley ACMD and South Coast AQMD live in zip codes classified as DACs.

\subsection{Additional EFMP implementation details}

The ARB sets general rules for the pilot program which administrators must follow. In both South Coast and San Joaquin Valley, the AQMDs are responsible for administering the program and determining household eligibility. In addition, the AQMDs must build a network of participating dealerships that agree to a set of consumer protections, including "no-haggle" posted prices, limitations on dealership financing, required information provision and inspec-

\footnotetext{
${ }^{11}$ Appendix figure A2 summarizes the components of the CES score.

${ }^{12}$ The EFMP program also offers subsidies of approximately equal magnitude that are available according to slightly different rules and eligibility criteria, but do not rely on the DAC designation. These are netted out in our empirical design and are not used to identify our parameters of interest.
} 
tion for used vehicles.

But, the ARB granted each district substantial latitude with respect to implementation, and specifically, marketing, outreach and the application process. In the South Coast AQMD, information about the program is relayed through marketing and participants apply online. After the AQMD determined an applicant is eligible, the program directs the applicant to contact the list of pre-approved dealerships. In San Joaquin Valley, the program is administered through regular "Tune-in and Tune-up" events on weekends and other direct outreach events throughout the San Joaquin Valley, specifically targeting minority groups. Eligible buyers are then guided through the application process and, if eligible, are directed towards the websites of participating dealerships.

\subsection{Data and summary statistics}

We merge three datasets: (1) disadvantaged community designations available from CalEPA, (2) program rebate data and (3) transaction-level data on the universe of new and used EVs purchased by California buyers.

The DAC designations are publicly available at the census tract level. ${ }^{13}$ Following the program rules, we map census tracts to zip codes and classify a zip code as disadvantaged if it contains part or all of a disadvantaged census tract. The EFMP rebate data are publicly available at the transaction-level. For each transaction the data report value of the subsidy, the vehicle purchased and the zip code in which the recipient of the subsidy lives. Our vehicle transaction data was purchased from a major market research firm. For the universe of battery electric vehicles ("BEVs") and plug-in hybrid vehicles ("PHEVs") purchased by buyers in California, we observe the make, model and model-year of the vehicle, the transaction price as reported to the Department of Motor Vehicles, the zip code of the buyer and the dealership that sold the vehicle.

We summarize transaction counts, prices and subsidies in table 2, grouping zip codes by whether they are in or out of the participating pilot regions $(A Q M D=1)$ and whether they are classified as a disadvantaged zip code (DAC $=1)$. Roughly half of the population of California resides in the participating AQMDs, of which the majority live in communities classified as disadvantaged for purposes of the AQMD pilot program. Outside of the pilot regions, a higher fraction of the population lives in non-disadvantaged zip codes, reflective of higher incomes and the fact that the South Coast AQMD and the San Joaquin Valley are locations with

\footnotetext{
${ }^{13}$ See https://oehha.ca.gov/calenviroscreen/report/calenviroscreen-version-20
} 
relatively poor air quality.

Buyers in disadvantaged zip codes purchase less expensive and fewer EVs on a per capita basis, before and after the start of the EFMP pilot. Yet, foreshadowing our empirical results, per capita EV sales rise most quickly in disadvantaged zip codes in the participating AQMDs. That said, EFMP transactions are a small fraction of overall EV sales. In disadvantaged communities during the pilot program, roughly two percent of the transactions received an EFMP subsidy. ${ }^{14}$

Consistent with the construction of the disadvantaged community identifier, these communities are less-advantaged along a number of sociodemographic indicators. In the first three columns of Table 3, we present population-weighted average demographics for all of California (column 1), disadvantaged communities outside the pilot regions (column 2) and disadvantaged communities outside the pilot regions (column 3). Relative to all of California, households in disadvantaged communities tend to have households incomes that average ten to fifteen thousand dollars lower than the mean household in California, are less likely to have graduated from high school, are more likely to be Hispanic or African American and are more likely to be unemployed. Yet, relatively to the averages for California, disadvantaged communities are less unusual than the set of zip codes associated with EV adoption through 2018. In column 4, present the summary statistics weighting by historical EV sales. Consistent with the evidence from Borenstein and Davis (2016), the sociodemographics of zip codes of early adopters of EVs suggest these zip codes are a particularly advantaged subset of California, with mean incomes roughly thirty-five thousand dollars higher than the average California household, higher educational attainment and lower rates of unemployment.

\section{Methodology}

The features of EFMP program lend themselves to a difference-in-differences specification comparing disadvantaged in and out of the two participating AQMDs, before and after the start of the pilot program. ${ }^{15}$ We can extend this to include an additional difference, by including the non-disadvantaged communities in and out of the participating AQMDs. Using this framework, we estimate three policy parameters of interest: (1) the incidence of the EFMP subsidies and (2) impact of the EFMP incentives on electric vehicle adoption, and (3) the elasticity of

\footnotetext{
${ }^{14}$ We do observe a small number of subsidies (rough $2 \%$ of the total) provided to households that, according to the subsidy data, live in zip codes that are not classified as disdvantaged.

${ }^{15}$ While the discontinuous nature of disadvantaged community assignment might suggest a regression discontinuity design is appropriate, the means-testing of the program causes most of the relevant variation to occur well away from the discontinuity. This can be seen in Appendix Figure A4.
} 
demand for alternative fuel vehicles, specifically amongst low- and middle-income customers targeted by the EFMP.

We aggregate our transaction-level data to the zip-quarter, the finest level of temporal and spatial disaggregation for which we have subsidy data, and the geographic level of treatment assignment. ${ }^{16}$ We consider a zip code as treated if the zip code is located in the South Coast or San Joaquin Valley Air Quality Management Districts ("AQMD=1"), contains at least part of one DAC census tract ("DAC=1") and the calendar date is in the third quarter of 2015 or later ("Post=1").

\subsection{Difference-in-differences specification}

To retrieve a difference-in-differences estimate of the intent-to-treat effect of the incentive on the price paid by the buyers or the impact on EV sales, comparing disadvantaged communities in and out of the pilot regions, one could estimate

$$
Y_{z t}=\alpha_{1} \mathbf{1}_{A} \mathbf{1}_{P}+v_{t A}+\gamma_{z}+\epsilon_{z t}
$$

where $Y_{z t}$ is the dependent variable of interest, $\mathbf{1}_{A}$ and $\mathbf{1}_{P}$ are indicators for AQMD=1 and Post=1, respectively. Zip code and AQMD-by-quarter-by-year effects are conditioned out via $\gamma_{z}$ and $v_{t A}$. Here, the coefficient $\alpha_{1}$ reflects an estimate of the intent-to-treat for buyers in disadvantage zip codes in the pilot region.

In our context, the magnitude of $\alpha_{1}$ will depend mechanically on the proportion of EV transactions that receive the EFMP subsidy. As noted in table 2, even in the treated zip codes, the number of EFMP subsidies is small, on average, relative to the total number of EV sales. Thus, we anticipate the intent-to-treat estimates to be equivalently small as they reflect the average of a few treated transactions with many transactions for which the subsidy was not claimed. We construct a continuous treatment variable, $\lambda_{z t}$, to be the fraction of EV purchases that receive an EFMP subsidy in each zip-quarter.

$$
\lambda_{z t}=\frac{\sum_{i} \mathbf{1}\left(\text { Subsidy }_{i z t}>0, \text { zip }=z, \text { time }=t\right)}{\sum_{i} \mathbf{1}(z i p=z, \text { time }=t)}
$$

Using $\lambda_{z t}$ as a continuous treatment in place of the treatment dummy in (1), we estimate

\footnotetext{
${ }^{16}$ The data on EFMP reports the quarter of purchase and the owner's zip code, but does not provide the Vehicle Identification Number ("VIN") of the purchased vehicle. Thus, we cannot match information on EFMP subsidies to exact transactions in the purchase data. Rather, we observe the mean EFMP subsidy received by EVs purchased by households at the zip-quarter level.
} 
the treatment-on-treated, $\beta_{1}$. Intuitively, this scales up the intent-to-treat estimate $\alpha_{1}$ to reflect that $\lambda_{z t}$ fraction of the transactions in each zip-quarter that are affected by the EFMP program. It is reflected in equation (3):

$$
Y_{z t}=\beta_{1} \lambda_{z t}+v_{t A}+\gamma_{z}+\epsilon_{z t}
$$

\subsection{Matched and triple-differenced specifications}

Retrieving an unbiased causal estimate from the difference-in-difference specification requires parallel pre-trends and the absence of omitted variables correlated with the treatment in the post-period. Figure 3 plots trends in the residual purchase price of electric vehicles, after conditioning on make*model ${ }^{*}$ mode-year fixed effects (left panel), and the log of EV sales (right panel) in disadvantaged zip codes in and out of the pilot regions over time. In each graph, the red lines and shading corresponds to the means and standard errors for disadvantaged communities in the participating AQMDs; the blue lines and shading plot the analogous values for disadvantaged communities in non-participating AQMDs. In both cases, the pre-trends are statistically indistinguishable. The slight different in the pre-trends for residual purchase prices as modest in comparison to the value of the EFMP incentives.

Our empirical context allows for two additional specifications to further address potential concerns with pre-period trends (despite the fact that the pre-trends for log-quantity are close to parallel) and omitted variables correlated with the treatment. Although the classification for disadvantaged communities applies identically to both the pilot and non-pilot regions, the histograms of CES scores plotted in Figure 2 indicate that the upper tail of CES scores in participating AQMDs does not overlap with the non-participating AQMD distribution. The highest CES score outside of the participating AQMDs (South Coast and San Joaquin) is 59.9, corresponding to the 75th percentile of CES scores in the participating AQMDs. If pre-trends differ for disadvantaged zip codes with extremely high CES scores relative to disadvantaged zip codes outside of the participating AQMDs, our estimates will be biased. Additionally, if adoption or pricing for zip codes in the very upper tail of the CES distribution changes for reasons unrelated to the EFMP program, the differences-in-differences specification may mis-estimate the treatment effect.

As a refinement to the difference-in-difference specification above, we use nearest-neighbor matching to pair disadvantaged zip codes in participating AQMDs with "control" disadvantaged zip codes in non-participating AQMDs. We match based on the pre-period trends in average prices or quantities, following the synthetic control literature (e.g. Abadie and Gardeaz- 
abal (2003), Abadie et al. (2010)). ${ }^{17}$

We also consider a triple-differenced specification that leverages the non-disadvantaged communities in both the pilot and non-pilot regions, and includes a full-set of interaction fixed effects, $v_{t A}, \phi_{t D}$ and $\gamma_{z}$, capturing shocks common to the pilot region, shocks common to disadvantaged communities and time-invariant zip-level differences.

$$
Y_{z t}=\beta_{1} \lambda_{z t}+v_{t A}+\phi_{t D}+\gamma_{z}+\epsilon_{z t}
$$

Relative to the unmatched and matched difference-in-difference specifications above, the triple-differenced specification controls for unobservable shocks to EV adoption or prices common to all zip codes within the pilot region. In our context, such shocks might arise if electric vehicles became more popular throughout a pilot region due to a local policy change affecting both advantaged and disadvantaged zip codes. If such a shock affected disadvantages and non-disadvantaged zip codes, the triple-differenced approach will net out the impact of the local policy change.

\subsection{Instrumental Variables}

In the purchase data, we do not observe which specific transactions received subsidies. Hence, our primary variables of interest are the EFMP-share of total transactions and the average subsidy across all transactions. Both are constructed by normalizing by the total quantity of EVs in a zip*quarter. As total transactions are the denominator of our scaled variables of interest, we would expect the OLS coefficient to be biased downward in log-quantity regressions.

We address this by instrumenting for the EFMP-share and for average subsidies in our main specification. We instrument for EFMP-share using linear and quadratic values of the count of EFMP-subsidized transactions in zip $z$ at time $t$, normalized by mean number of transactions in that zip for the ten quarters up until the start of the pilot program. ${ }^{18}$

As we report in our regression tables, the instrument is sufficiently strong - zip codes with high adoption in the pre-period tend to have higher levels of adoption in the post period. And by construction, the denominator of the instrument is constant for each zip code and hence, uncorrelated with idiosyncratic shocks to log quantities in the post-treatment period. We report

\footnotetext{
${ }^{17}$ We plot the mean residual purchase price and the mean of log of EV sales (right panel) in the matched sample in A5.

${ }^{18}$ Formally, denoting the number of periods before the start of the pilot program as $T$, the quarter in which the EFMP program becomes active as $t^{*}$ and number of transactions in zip $z$ in quarter $t$ as $Q_{z t}$, we construct the instrument for EFMP-share as $I V_{z t}=\frac{\text { EFMP Subsidy Count } \text { z }_{z t}}{\sum_{r<t^{*}} Q_{z r} / T}$.
} 
both the first-stage f-statistics and the Sargan-Hansen p-values for the instruments.

\section{Results}

\subsection{Pass-through of EFMP subsidies}

Our first parameter of interest is the pass-through of the EFMP incentives to buyers. Cost effectiveness of the program is determined in part by the extent to which the subsidy affects the price paid by the consumer, rather than accruing to dealerships or manufacturers. To estimate incidence of the incentives, we must first describe how the composition of EVs affects our empirical approach.

As discussed above, we aggregate our data to the zip-quarter level, as that is the finest level of aggregation for which the subsidy data are available. It is also the geographic level of assignment to treatment. However, the EFMP program offers incentives for households to purchase both new and used EVs. This shifts the composition of vehicles purchased in response to the program. ${ }^{19}$ Consequently, the mean price for all vehicles purchased in a zip-quarter reflects both the incidence of the program and any compositional shift induced by the incentive.

To control for compositional changes and to isolate the pass-through of the incentive, we condition on the mix of vehicles purchased in a zip-quarter by regressing transaction-level vehicle prices on model*model-year*year-of-purchase fixed effects, odometer reading in miles and a dummy variable reflecting whether or not the vehicles was leased. Formally, denoting vehicle, zip, model, model year and year-quarter of purchase as $i, z, m, y$ and $t$ respectively, we regress:

$$
\text { SellPrice }_{i z m y t}=\alpha_{m y t}+\beta_{1} \text { Odometer }_{i}+\beta_{2} \text { Lease }_{i}+\mu_{z t}+\epsilon_{i}
$$

where SellPrice izmyt $_{\text {is }}$ is thansaction price of the vehicle $i$ received by the seller. In this context, $\mu_{z t}$ captures whether dealerships in a particular zip code received more or less than the statewide average for vehicles of identical make and model-year (e.g., 2015 Nissan Leaf) purchased in the same quarter and year (e.g., first quarter of 2017). Interpretation of the pass-through regressions is a bit more straightforward using the price buyers paid net of subsidies as the dependent variables. Thus, we net out the average subsidy in zip $z$ and time $t$ to construct our

\footnotetext{
${ }^{19}$ Although the EFMP data does not report the vehicle VIN, the public data does record the model year of the purchased vehicle. Roughly 80 percent of vehicles have models years more than one year less than the calendar year in which they are purchased, suggestive that they are used, rather than new vehicles. In contrast, 87 percent of all EVs in the transaction data would be classified as used by this definition.
} 
dependent variable:

$$
\text { ResidualBuyPrice }_{z t}=\mu_{z t}-\overline{E F M P}_{z t}
$$

where $\overline{E F M P}_{z t}$ is the average EFMP subsidy received in the zip-quarter. Intuitively, ResidualBuyPrice reflects whether buyers in the zip-quarter paid more or less that the statewide average, net of any subsidies received.

We estimate two specifications that capture slightly different measures of pass-through. First, we regress our dependent variable on the fraction of sales that received an EFMP subsidy in a zip-quarter:

$$
\text { ResidualBuyPrice }_{z t}=\beta_{1} \lambda_{z t}+v_{t A}+\gamma_{z}+\epsilon_{z t} \text {. }
$$

The estimate of $\beta_{1}$ measures the change in the price paid for vehicles by recipients of the EFMP subsidy, relative to buyers of the same model and vintage who did not receive the EFMP subsidy. ${ }^{20}$ We also estimate the pass-through directly on the price paid by buyers directly via the following equation:

$$
\text { ResidualBuyPrice } z=\gamma_{1} \overline{E F M P}_{z t}+v_{t A}+\gamma_{z}+\epsilon_{z t}
$$

We interpret the coefficient $\gamma_{1}$ as the fraction of the subsidy captured by buyers as opposed to dealers or other upstream market participants. Table 4 displays results from equations (7) in the top panel and (8) in the bottom panel. For each, the first three columns present the OLS estimates for the difference-in-difference, the matched difference-in-differences and the tripledifferenced specifications respectively. Columns 4 through 6 recreate these specifications using our preferred instrument.

We find relatively consistent evidence that consumers capture the majority of the subsidy. Relative to an average subsidy close to $\$ 5,000$, our OLS results suggest that buyers with the subsidy pay $\$ 2,954$ to $\$ 3,715$ less for a vehicle, net of the subsidy, relative to non-participants purchasing the same make, model and model-year elsewhere in California. After instrumenting, the effect on prices rises modestly. We estimate EFMP subsidies reduce the price to the buyer, net of subsidies, by an average of $\$ 4,673$ to $\$ 5,304$.

These results are echoed in panel B, which presents our estimates of the rate of subsidy passthrough. We find that buyers capture the majority of the subsidy, between 57 and 76 percent of the subsidy in the OLS specifications and between 94 to 108 percent in the IV specifications. In

\footnotetext{
${ }^{20}$ By construction, the average residual buy price in a zip-quarter is given by, ResidualBuyPrice $z t=\lambda_{z t}\left(P_{0}-S\right)+$ $\left(1-\lambda_{z t}\right) P_{0}=P_{0}-\lambda_{z t} S$, where $P_{0}$ and $S$ denote the price paid by non-recipients and the dollar value of the subsidy received by the EFMP recipient. Estimating (7), $\beta_{1}$ provides an estimate of $S$.
} 
all cases, the pass-through estimates are indistinguishable from full pass-through, suggesting that consumers capture the lion's share of the subsidy and consistent with stated efforts on the part of program designers who sought to channel most of the subsidy dollars to buyers rather than sellers or upstream market participants. Our pass-through estimates are consistent with previous work examining the pass-through of earlier hybrid vehicles subsidies. Gulati et al. (2017) finds that new vehicle buyers with access to subsidies capture 80 to 90 percent of the value of an incentive. ${ }^{21}$ But, unlike earlier subsidy programs that were widely available, the EFMP program pilot was limited in scope. Although we find evidence that consumers captured the vast majority of the benefits of the pilot program, the pass-through of a widely implemented program might differ.

\subsection{Impact of EFMP subsidies on adoption}

We use similar specifications to estimate the response of demand to the program replacing ResidualBuyPrice $_{z t}$ with the log-quantity of sales as the dependent variable in equations (7) and (8).

Table 5 shows the effect of the EFMP subsidies on the quantity of EVs transacted. As with the price regressions, we present OLS estimates in columns 1 through 3 , for the difference-indifferences, matched difference-in-differences and triple differenced specifications respectively, and IV results in columns 4 through 6.

In panel A, we regress log quantities on the fraction of EFMP sales and interpret the estimated coefficient as the percentage change in EV sales resulting from EFMP program exposure moving from zero to 100 percent eligibility. Our OLS results suggest that zip codes in which all buyers were eligible for the program would experience, on average, a 26 percent $(=100 x(\exp (0.23)-1))$ increase in the quantity of new EVs purchased relative to zip codes with zero program eligibility. The point estimates are similar across the three specifications, as we would anticipate given the relatively similar pre-trends in log quantities graphically presented in Figure 3.

As we note in the discussion of the instrument above, the structural endogeneity created by quantity appearing on both the right and left-hand sides would bias the OLS estimate of EFMP on sales downwards. The IV results in columns 4 through 6 confirm this. The preferred

\footnotetext{
${ }^{21}$ Gulati et al. (2017) further finds that subsidy-eligible buyers are more likely to choose vehicle options that increase the purchase price of the vehicle, and thus pay a higher purchase price, unadjusted for options. In our case, we do not observe the options purchased by customers. However, EFMP buyers are substantially more likely to purchase used EVs, where the set of potential options is more limited. Moreover, unobserved options would tend to bias our estimates towards zero, suggesting, if anything our results understate the fraction of the subsidy captured by consumers.
} 
IV point estimates are more than double the OLS estimates, at .64 to .69 log-points for the unmatched and matched difference-in-differences specifications, respectively. The bottom panel presents estimates of the percentage change in EV sales from offering a $\$ 1,000$ subsidy. In our IV specifications, we estimate a $\$ 1,000$ subsidy increases adoption by 0.13 to 0.14 log-points.

\subsection{Elasticity of demand for electric vehicles}

Finally, we are interested in estimating the elasticity of demand for EVs. This is of particular interest as estimates of the elasticity of demand for early adopters reflect the price sensitivity of primarily high-income households. In contrast, the EFMP program specifically targets low and middle-income households that form the bulk of the population and potentially play an important role in wide-scale adoption of EVs.

We approach this in two ways. First, we can use the estimates from tables 4 and 5 to back out the elasticity of demand of EFMP-eligible buyers as:

$$
\varepsilon_{Q_{E}}^{P}=\frac{\phi}{\beta} P_{E}
$$

where $\beta$ is the fraction of the subsidy captured by buyers and $\phi$ is an estimate of the impact of a $\$ 1,000$ subsidy on demand for EVs. ${ }^{22}$

Assuming complete pass-through (100\%) and the impact of a $\$ 1,000$ subsidy (0.13) from column 4 of Tables 4 and 5, and the average price of eligible vehicles in EFMP locations, we have an estimate of the elasticity of demand for EFMP-eligible buyers, $\varepsilon_{Q_{E}}^{P} \approx-\frac{0.17}{1.00} * 26=-3.4$.

Alternatively, we can estimate the elasticity directly by regressing log quantity on the percent premium or discount at which EVs were sold in the zip-quarter. Formally, we estimate:

$$
\log \left(Q_{z t}\right)=\beta \% \text { Premium }+v_{t A}+\gamma_{z}+\epsilon_{z t}
$$

where \%Premium is calculated as ResidualBuyPrice $z$ normalized by mean price of EVs in our data. As in earlier specifications, we present both the OLS estimates and the IV estimates. Table 6 presents elasticity estimates obtained directly from the regressions, which vary in a tight range from -3.2 to - 3.3, depending on specification. Across all methods, our estimates are larger than recent estimates in the literature for the elasticity of early adopters. ${ }^{23}$ This suggests that low- and middle-income buyers are more price elastic than higher-income earlier adopters.

\footnotetext{
${ }^{22}$ See appendix section A.3 for the derivation.

${ }^{23} \mathrm{Li}$ et al. (2017) uses gasoline prices as an IV and estimates a demand elasticity of -1.3. Springel (2017) and Li (2017) both use BLP IVs to retrieve estimates of -1.0 to -1.5 (Springel) and -2.7 (Li), respectively.
} 


\subsection{Supplementary results}

\subsubsection{Effects by air district}

We do not separately estimate the effects by AQMD in our main results. Yet, program rules allow each air district flexibility in the operation of the pilot program. Although ARB rules specify the incentive generosity schedule and set general guidelines related to dealership participation, the districts choose to how to market the program, handle applications and coordinate with participating dealerships.

The program in South Coast operates largely through its online presence, with a relatively modest amount of targeted marketing. Interested consumers apply on-line, at which time the air district verifies that they have a eligible trade-in. After being pre-approved, they contact a participating dealership and select a vehicle. The air district then confirms that the vehicle is eligible for the incentive (i.e., not subject to recalls), that the financing meets program requirements, and that the household has not participated in the program previously. If approved, the air district contacts the dealership and the transaction is completed, with the buyer paying the price of the vehicle less the EFMP incentive.

In contrast, the program in San Joaquin engages in direct marketing to low-income and minority households. During the study period, entry into the program occurred exclusively through in-person attendance at local "Tune-in, Tune-up" smog testing events. ${ }^{24}$ "Tune-in, Tune-up" events occur every couple of weeks, and rotate between regional population centers in the San Joaquin Valley. Interested individuals bring their current vehicle to an event, receive a free smog check and, if eligible for the program, receive in-person guidance on how to apply. At the same time, program officials verify applicant eligibility and guide the potential participant through the application process. After the event, officials follow up with potentialy applicants to help them complete their application. Once pre-approved, households are directed to dealership websites, all of which are required to post "no-haggle" prices (e.g., Carmax). Pending approval of a final selection by the air district, the transaction is completed and, as in South Coast, the buyer pays the price of the vehicle less the EFMP incentive.

Table 7 presents the results allowing the coefficients of interest to vary by air district. The four left-most columns report the OLS and IV results for prices, and the four right-most columns report the OLS and IV results for log quantities. All columns are based on the triple-differenced specification.

When disaggregating by AQMD, the average treatment effect on price is larger in San

\footnotetext{
${ }^{24}$ Since the end of the study period, program officials in the San Joaquin Valley have begun to take online applications.
} 
Joaquin Valley than in South Coast. These differences may reflect the greater guidance towards "no-haggle" dealerships with posted online prices given to program participants in the San Joaquin Valley. However, the differences are not large enough in magnitude to be statistically distinguishable. Likewise, point estimates for pass-through rates are higher in both the OLS and IV specifications for San Joaquin Valley, although again, the point estimates are not statistically distinguishable across the two regions, nor are individual pass-through estimates statistically distinguishable from complete pass-through of the subsidies to buyers.

Columns 5 through 8 present the results for EV sales. Again, the point estimates for the effect on sales are slightly higher for San Joaquin Valley compared to South Coast, although again, the estimates are statistically indistinguishable. We estimate that each $\$ 1,000$ in subsidy increases EV adoption by 9 and 16 percent in South Coast and San Joaquin Valley, respectively. Although again, the point estimates are statistically indistinguishable, the higher point estimate for the San Joaquin Valley program might reflect the more intensive marketing and guidance provided by the program administrators.

\subsubsection{Price effect on non-participants}

An implicit assumption in the analysis above is that the EFMP does not affect the price paid by individuals living in the program areas who were not eligible through, for example the program acting as a shock to aggregate demand. Put formally and ignoring fixed effects for simplicity, the mean residual buy price, by construction, is an average of the price for recipients (fraction $\lambda_{z t}$ ) and non-recipients (fraction $1-\lambda_{z t}$ ). Denoting the price for non-recipients, $P_{0}$ and the dollar value of the subsidy captured by a recipient, we can denote the average price as:

$$
\text { ResidualBuyPrice }_{z t}=\lambda_{z t}\left(P_{0}\left(\lambda_{z t}\right)-S\right)+\left(1-\lambda_{z t}\right) P_{0}\left(\lambda_{z t}\right)=P_{0}\left(\lambda_{z t}\right)-\lambda_{z t} S
$$

If we regress ResidualBuyPrice $z$ on a constant and $\lambda_{z t}$, as in:

$$
\text { ResidualBuyPrice }_{z t}=\alpha+\hat{\beta}_{1} \lambda_{z t}+v_{z t}
$$

and $\frac{d P_{0}\left(\lambda_{z t}\right)}{d \lambda_{z t}}>0$, our specification would overestimate the true change in the sales price net of subsidies paid by program participants.

Two features of our context suggest that the relationship between $P_{0}$ and $\lambda$ is unlikely to significantly bias our estimates of pass-through and the amount of the subsidy captured by the consumer. First, the fraction of buyers who receive the EFMP is small-in "treated" zips, two 
percent of vehicles on average receive an EFMP subsidy. Thus, the impact of the program on the prices paid by non-participants is likely to be modest. Second, our level of analysis is at the zip-quarter level despite the fact that zip codes themselves are not isolated markets. Rather, these zip codes are part of large metro areas across which people purchase vehicles. Vehicles commonly flow between metro areas in response to local supply and demand conditions. If the program led to a substantial increase in the prices paid by non-participants within the zip code, market forces would tend to arbitrage away a local premium for a specific vehicle. Thus, we consider it unlikely that the small fraction of buyers who receive EFMP subsidies have a meaningful impact on the prices paid by the vast majority of buyers who do not.

Yet, the details of the program allow us to test for spillover effects directly by examining the effect of EFMP-induced demand on prices in zip codes outside the participating air quality districts. We implement this by restricting the sample to sales outside the participating regions and collapsing the data to quarter-of-sample by make/model-year observations. We then regress the average residual sales price on the share of vehicles purchased under the EFMP in that quarter. Conceptually, we compare average prices for make/model-years popular amongst EFMP buyers to those unpopular amongst EFMP buyers. If the treatment influences the prices paid in non-participating regions, we would expect the average prices of popular models to increase in non-participating regions after the start of the EFMP program relative to the prices of unpopular models.

$$
P_{t, A Q M D=0}^{M M Y}=\alpha s_{t}^{M M Y}+X_{t}^{M M Y}+\epsilon_{t}^{M M Y}
$$

In equation 13, MMY differentiates vehicles based on make and model-year, and the quarterof-sample is denoted by $t$. The coefficient of interest is $\alpha$, which will be positive if the statewide share of MMY cars sold under the EFMP program increases the price of those cars in nonparticipating regions.

We find that a small but statistically insignificant effect exists. The change in $s_{t}^{M M Y}$ from zero to one represents a shift from zero percent to 100 percent of MMY vehicles being sold under the EFMP program. Our estimate shows that this would, on average, increase the transaction prices by $\$ 4,486$. Adjusting for the share of EVs sold under EFMP (1.2 percent overall), this implies an average increase of $\$ 53$ for each such vehicle sold in non-participating AQMDs. Adjusting instead by share of used EVs sold under EFMP (3.5 percent), it would imply an average increase of $\$ 157$ per vehicle in non-participating AQMDs.

The existence of these effects implies that the "true" treatment effect on EV prices reported 
in Table 4 may be slightly overstated, and one may wish to adjust these coefficients towards zero by $\$ 50-\$ 150$ when interpreting these results. The qualitative and policy implications are unaffected, however, as these spillover effects are one-to-two orders of magnitude smaller than the average treatment effect on treated vehicles. Moreover, the presence of these market adjustments reflects the efficiency with which vehicle markets operate.

\section{Policy Discussion}

Estimates of the demand elasticity and rate of subsidy pass-through are important policy parameters to any jurisdiction considering EV subsidies. A present-day example is the state of California, which is currently in the legislative process that will determine the next allocation of state EV rebate funds intended to push the state across the target goal of 1.5 million EVs on the road by 2025. The demand elasticity and rate of subsidy pass-through are central to the question of how much funding would be required to achieve this goal. As table 3 illustrates, the demographics of disadvantaged zip codes are much closer to the mean demographics in California than the demographics of the zip codes in which electric vehicles were purchased through the end of 2017. If reaching the ambitious EV adoptions targets necessitates widerspread adoption than historical experience, this paper's evidence on the impact of incentives on lower-income communities provides an important guide.

There are several policies that reduce the retail price of EVs, including federal tax incentives, state consumer subsidies and supply-side policies like California's ZEV mandate, only some of which impose a direct fiscal cost on the state budget of California. As it is difficult to predict the exact form of state and federal subsidies in the future, we present a back-of-the-envelope calculation intended to approximate the total cost across all sources of subsidies that apply to purchases of new EVs going forward. ${ }^{25}$

By the end of 2017 there were roughly 330,000 EVs on the road in California. The subsidyinclusive growth rate in the California EV fleet can be retrieved directly from the data. It was over 80 percent in 2014 and has steadily declined to 33 percent in 2017. In order to reach 1.5 million EVs in California by 2025, a 20.8 percent annual growth rate from 2018-2025 is required, after taking scrappage into account. ${ }^{26}$ In order to estimate the subsidy bill required to reach

\footnotetext{
${ }^{25}$ To be clear, an implicit assumption of this exercise is that the EFMP subsidy pass-through rate would be reflective of the pass-through rate of a much larger program. If a larger program had a lower pass-through rate, arising from perhaps sellers who anticipate that many buyers will have access to the subsidy, the necessary budgetary cost would increase.

${ }^{26}$ The rate of used EVs exported to other states or countries, totaled in accidents, or scrapped due to old age or lack of use are each determinants of the number of EVs that will, at any point, be on the road.
} 
1.5 million EVs by 2025 , it is necessary first to establish a no-subsidy baseline growth rate that would be expected to occur from 2018 - 2025 in the absence of subsidies. This is easily retrieved using the demand elasticity estimated earlier. Finally, we use our elasticity estimates again to calculate how much the purchase price of EVs would have to decline to shift from the no-subsidy baseline growth rate to the necessary 20.8 percent average growth rate. This procedure requires some assumptions, which we now describe.

The baseline rate of EV demand growth is a function of factors such as consumer preferences, relative prices and attributes of vehicles (e.g. battery range), the price of fuel inputs (gasoline versus electricity), macroeconomic and credit conditions, and many other potential considerations. The raw growth rate has been influenced by the presence of major subsidy programs, both federally and at the state level. In order to net out these subsidies and retrieve a no-subsidy baseline growth rate, we proceed under several conservative assumptions. ${ }^{27}$ We assume a retrospective average new EV price of $\$ 35,000$, and $\$ 10,000$ in cumulative state and federal subsidies captured by consumers. Based on the preferred demand elasticity of -3.3 from our empirical estimates, we estimate no-subsidy growth rates in 2015, 2016 and 2017 of 32.3, 24.3 and 20.8 percent, respectively (Table A1). These reflect the growth rate that would have occurred if state and federal incentives had not been present. Based on the historical pattern of new technology adoption, one would expect that the growth rate will continue to decrease over time as the market becomes more saturated. Therefore, we conjecture that a baseline growth rate between 2018 and 2025 of roughly 12 to 14 percent is conservative (again in the sense that it will likely be even lower, which would lead to even higher estimates of the subsidy requirement, all else equal).

Projecting forward, we need to make further assumptions about the vehicles purchased under a subsidy program and the rate at which on-road EVs exit the California fleet, either through accidents, exports out of California or scrappage. The subsidy program that we project is broadly consistent with the major existing subsidy programs - the California CVRP and the U.S. federal EV tax credit. Both of these programs offer subsidies for new EV purchases. To align this thought exercise most closely to our empirical results, we assume the going-forward (2018-2025) price of new EVs declines to $\$ 26,000$, which is roughly the weighted average price received by sellers for the mix of vehicles purchased under the EFMP program. An average sale price of $\$ 26,000$ is consistent with industry projections for entry-level EV models in 2025.

\footnotetext{
${ }^{27}$ Throughout this section, "conservative" is intended to describe an assumption that will lead to an under-estimate of the implied subsidy bill to achieve 1.5 million EVs by 2025. For example, a "conservative" assumption would lead to a higher baseline growth rate, thus reducing the subsidy bill requirement.
} 
This subsidy bill calculation is therefore consistent with a program that only applies to new vehicle purchases, similar to CVRP. We assume that 10 percent of the EV stock will be retired each year starting in 2020, capturing vehicle retirements, accidents and exports to other states and countries.

Table 8 presents the implied total value of EV subsidies that would be required for California to have 1.5 million EVs on the road by $2025 .^{28}$ The table presents the subsidy bill estimates for various assumed levels of annual baseline growth in the EV stock in the range of 10 to 16 percent between 2018-2025. The implied required change in buy-price is retrieved by assuming a list price of $\$ 26,000$ per $E V$ and applying estimates of the subsidy elasticity of demand to the implied required percent change in quantity.

Moving left-to-right, the columns assume higher baseline growth rates. Given the rate of historical decline in growth (which is natural in rapidly-growing markets), an expected annual growth rate of 12-14 percent from 2018-2025 seems to us to be plausible and even optimistic. Moving from top-to-bottom in the table, the demand elasticities are increasing and we assume demand to exhibit constant elasticity throughout this range. The top row elasticity of -2.0 reflects the middle of the range of elasticity estimates from the literature. The elasticity estimated in this paper is in the range of -3.2 and -3.3 , with -3.3 reflected in the bottom row.

As baseline growth rates increase, the necessary change in the price of new EVs and the cumulative subsidy bill both decline. This reflects a diminished need for policy intervention in order to achieve a given target EV adoption goal. The implied change in prices and subsidy bill also declines if we assume that demand is more elastic, such that a subsidy of a given value has a greater impact on the rate of EV adoption, all else equal.

Together, these estimates reflect the need for a substantial EV subsidy bill. Given our conservative approach to assumptions, the subsidy bill estimates presented in the table should be interpreted as lower bounds. In no scenario presented here is the estimated subsidy bill floor below $\$ 7.7$ billion. Moreover, the underlying parameters support a wide range of possible subsidy bills that extends well above $\$ 20$ billion. The range implied by our elasticity estimates and that correspond to 12-14 percent baseline growth is no less than $\$ 12$ to $\$ 18$ billion dollars. Given that our elasticity estimates in this paper are larger than those published in the existing literature, one may wish to know the subsidy bill estimated from a smaller elasticity. An elasticity of -2.0 implies a subsidy bill floor in the range of $\$ 18.0$ to $\$ 26.9$ billion dollars from 2018-2025. The presence of federal subsidies, or implicit subsidies such as the ZEV mandate,

\footnotetext{
${ }^{28} \mathrm{~A}$ more detailed description of the methodology used for these estimates can be found in Appendix section A.4.
} 
would reduce the amount for which California would be directly responsible. ${ }^{29}$

\section{Conclusion}

In this paper we exploit variation arising from rules governing the availability of EV subsidies in California. Using a unique dataset of both transaction prices and subsidy levels, we estimate the elasticity of demand amongst low- and middle-income households and the fraction of the subsidy captured by consumers. It is difficult to estimate these statistics in a credible way when examining many of the other EV rebate policies that have been available in the California and the United States in recent years. Both the federal EV tax credit and the California Clean Vehicle Rebate Program subsidies were (until recently) available to any EV buyer in their jurisdiction, making it difficult to construct a credible control group.

The rules governing the EFMP Plus Up program in California are well suited to deploying a triple-difference methodology in program evaluation. When we do, we estimate a subsidy elasticity of EV demand of -3.3, and a subsidy pass-through rate of 100 percent. Assuming that these statistics are generalizable, we use them to estimate the cumulative amount of additional subsidy dollars that will be required for California to meet its goal of having 1.5 million EVs on the road by 2025. Depending on the assumed baseline (no-subsidy) growth rate, our estimates imply that at least $\$ 12$ - $\$ 18$ billion in total subsidies will be required.

One contribution of this paper is the relevance of our estimates to low- and middle-income households. While most EVs to date are owned by wealthy households, mass electrification of the transportation sector will require adoption in the mass market. The means-testing and geographic targeting of the EFMP allow a rare opportunity to study the adoption decisions of lowand middle-income buyers, whose demand and price sensitivity may be lower than those of high income households. One instructive comparison is to benchmark our elasticity estimate of -3.3 against implied elasticities from the earlier literature on hybrid vehicle incentives that likely reflect the responsiveness of higher income, early adopters. Gallagher and Muehlegger (2011) and Chandra et al. (2010) exploit the timing and coverage of U.S. state and Canadian province hybrid vehicle incentives, and estimate that a $\$ 1000$ tax incentive was associated with 31 to 38 percent increase in hybrid vehicle adoption. Even if the incentives are fully passed through to consumers, the estimates imply responsiveness greater than our estimate for low-

\footnotetext{
${ }^{29}$ Note that our calculations hold the demand elasticity constant throughout the forecast period, which is another conservative assumption. As the size of the EV fleet grows, the demand elasticity could decline as percentage changes in quantity imply an ever-growing increase in the number of subsidy-induced EV sales.
} 
and middle- income households. In contrast, recent papers estimating the demand elasticity for early EV adopters (e.g., Li et al. (2017), Li (2017), and Springel (2017)) tend to estimate less elastic demand for early EV adopters. Either way, historical evidence of the effect of subsidies obtained by early adopters may prove a poor guide for policies requiring mass market adoption.

There are other reasons to believe that widespread adoption will encounter challenges that are not present in the EV market to date. In addition to a low stated willingness to pay for BEV technology (Helveston et al. (2015)), there is widespread lack of awareness of EV technology or capabilities (see, e.g., Egbue and Long (2012), Krause et al. (2013)) and consumers often fail to think about fuel prices in a systematic way (Turrentine and Kurani (2007)). EVs take hours to charge, and charging infrastructure will need to expand dramatically to meet the demand of a larger EV fleet. It is not yet known how well the electricity market will adapt to meeting a higher proportion of energy demand from the transportation sector, nor how the carbon intensity of electricity production will evolve to meet increasing vehicle charging demand.

\section{References}

Abadie, Alberto, Alexis Diamond, and Jens Hainmueller, "Synthetic control methods for comparative case studies: Estimating the effect of California's tobacco control program," Journal of the American statistical Association, 2010, 105 (490), 493-505.

— and Javier Gardeazabal, "The economic costs of conflict: A case study of the Basque Country," American economic review, 2003, 93 (1), 113-132.

Beresteanu, Arie and Shanjun $\mathrm{Li}$, "Gasoline prices, government support, and the demand for hybrid vehicles in the United States," International Economic Review, 2011, 52 (1), 161-182.

Borenstein, Severin and Lucas W Davis, "The distributional effects of US clean energy tax credits," Tax Policy and the Economy, 2016, 30 (1), 191-234.

Chandra, Ambarish, Sumeet Gulati, and Milind Kandlikar, "Green drivers or free riders? An analysis of tax rebates for hybrid vehicles," Journal of Environmental Economics and management, 2010, 60 (2), 78-93.

Clinton, Bentley and Daniel Steinberg, "Providing the Spark: Impact of Financial Incentives on Battery Electric Vehicle Adoption," Working Paper 2017. 
Egbue, Ona and Suzanna Long, "Barriers to widespread adoption of electric vehicles: An analysis of consumer attitudes and perceptions," Energy policy, 2012, 48, 717-729.

Gallagher, Kelly Sims and Erich Muehlegger, "Giving green to get green? Incentives and consumer adoption of hybrid vehicle technology," Journal of Environmental Economics and management, 2011, 61 (1), 1-15.

Gulati, Sumeet, Carol McAusland, and James M. Sallee, "Tax incidence with endogenous quality and costly bargaining: Theory and evidence from hybrid vehicle subsidies," Journal of Public Economics, 2017, 155, 93 - 107.

Helveston, John, Yimin Liu, Elea Feit, Erica Fuchs, Erica Klampfl, and Jeremy Michalek, "Will Subsidies Drive Electric Vehicle Adoption? Measuring Consumer Preferences in the U.S. and China," Transportation Research Part A, 2015, 73, 96-112.

Krause, Rachel M, Sanya R Carley, Bradley W Lane, and John D Graham, "Perception and reality: Public knowledge of plug-in electric vehicles in 21 US cities," Energy Policy, 2013, 63, 433-440.

Li, Jing, "Compatibility and Investment in the U.S. Electric Vehicle Market," Working Paper 2017.

Li, Shanjun, Joshua Linn, and Elisheba Spiller, "Evaluating "Cash-for-Clunkers": Program effects on auto sales and the environment," Journal of Environmental Economics and management, 2013, 65 (2), 175-193.

_, Lang Tong, Jianwei Xing, and Yiyi Zhou, "The market for electric vehicles: indirect network effects and policy design," Journal of the Association of Environmental and Resource Economists, 2017, 4 (1), 89-133.

Mian, Atif and Amir Sufi, "The Effects of Fiscal Stimulus: Evidence from the 2009 Cash for Clunkers Program," The Quarterly Journal of Economics, 127 (3).

Sallee, James M, "The surprising incidence of tax credits for the Toyota Prius," American Economic Journal: Economic Policy, 2011, pp. 189-219.

Springel, Katalin, "Network Externality and Subsidy Structure in Two-Sided Markets: Evidence from Electric Vehicle Incentives," Working Paper 2017. 
Turrentine, Thomas S and Kenneth S Kurani, "Car buyers and fuel economy?," Energy policy, 2007, 35 (2), 1213-1223. 
Figure 1: DAC Zip Codes, South Coast and San Joaquin Valley AQMDs

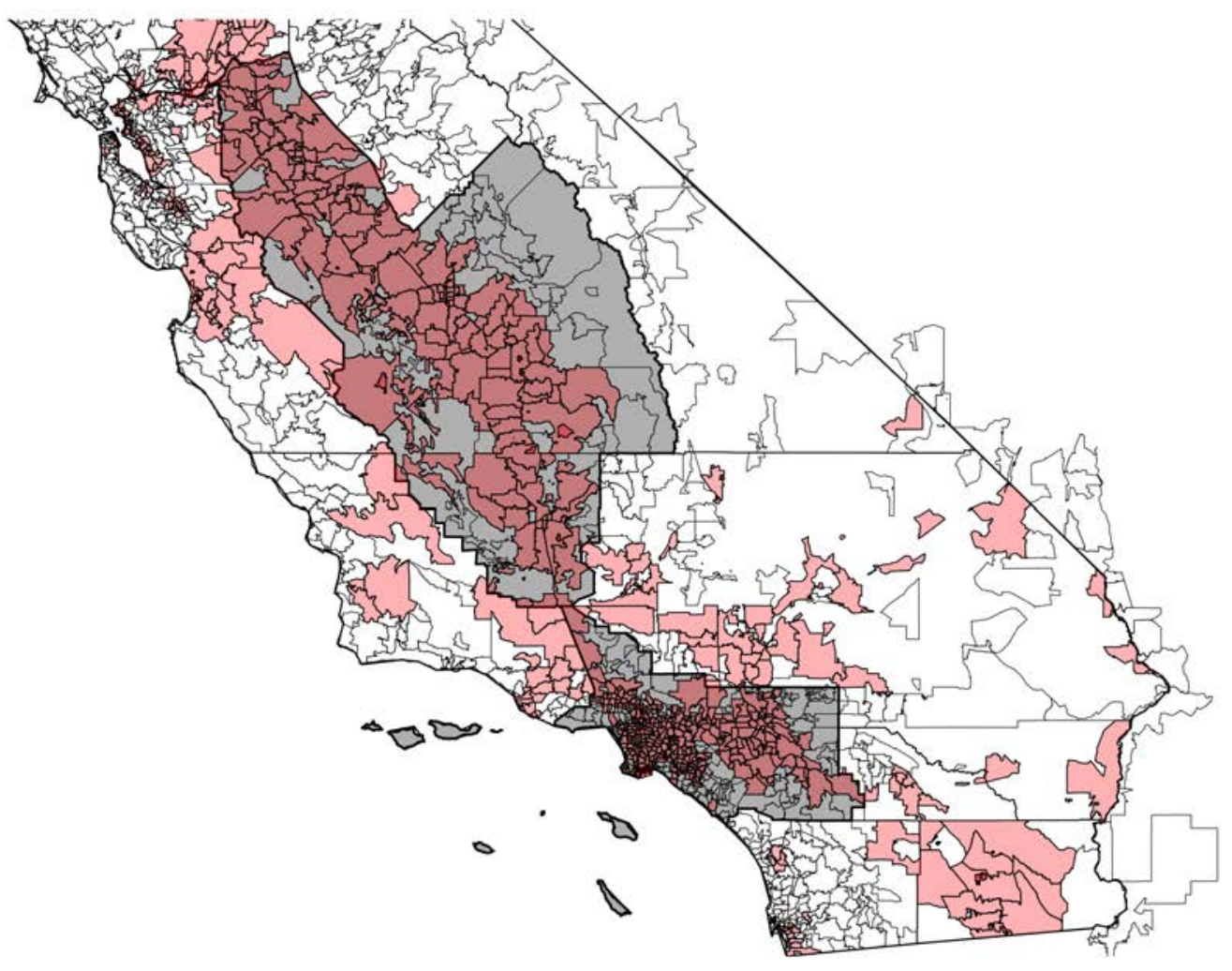


Figure 2: Average Income and Max-CES Score

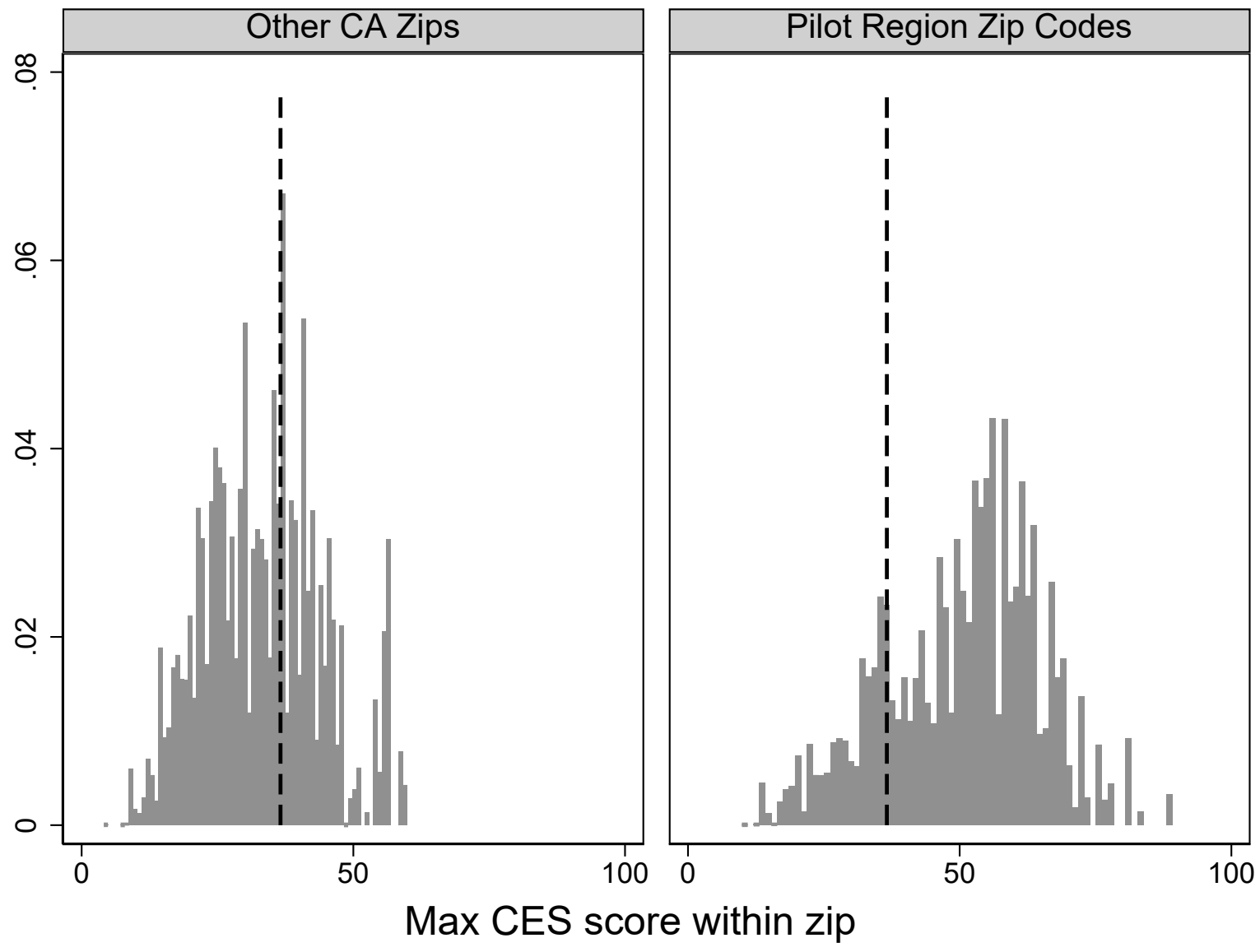

Note: Left histogram presents the distribution of zip-level maximum CES scores for non-pilot regions. Right histogram presents the distribution of zip-level maximum CES scores for the pilot regions. The dashed vertical line corresponds to the disadvantaged community CES score cutoff of 36.6. 
Figure 3: Trends in Prices and Quantities, Disadvantaged Communities in and out of Pilot Regions
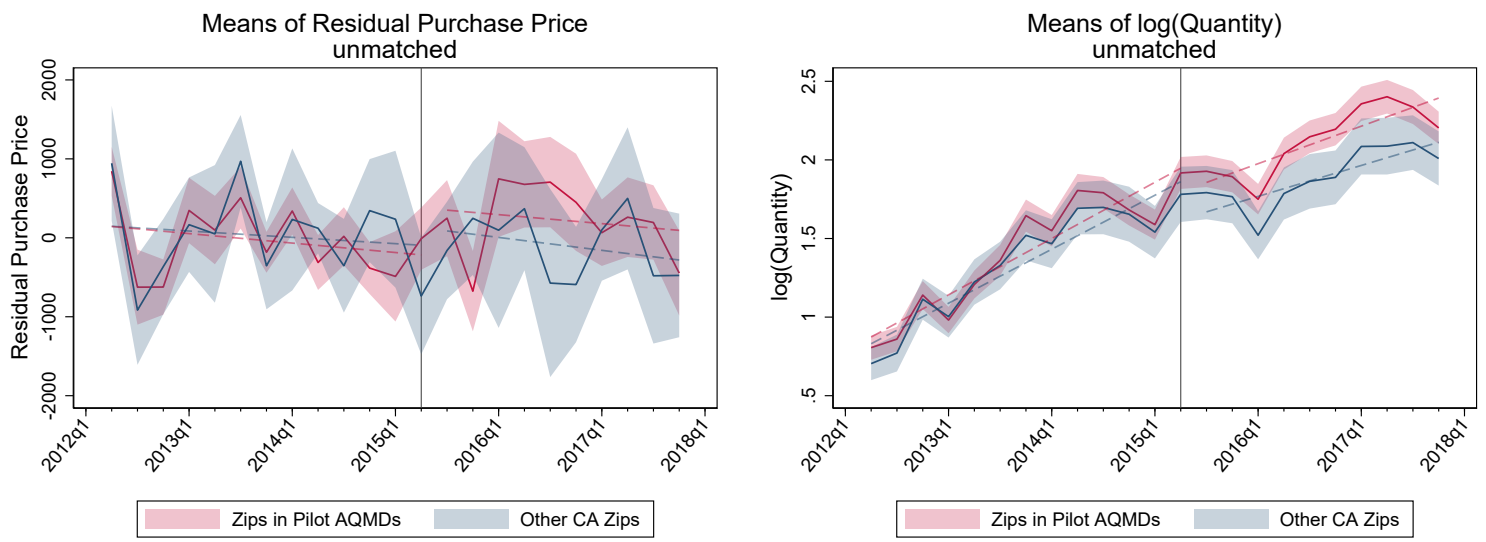

Note: Red and blue lines correspond to the unweighted average prices and log quantities in disadvantaged communities in and out of the pilot regions, respectively. Vertical line corresponds to the start quarter for the EFMP program. Price graphs plot the mean residual prices for disadvantaged communities in an out of the pilot regions after conditioning on make-model-modelyear fixed effects. 
Table 1: EFMP Incentive Schedule for BEVs and PHEVs

\begin{tabular}{cc}
\hline Income & Subsidy \\
\hline$<225 \%$ FPL & $\$ 5,000$ \\
$225-300 \%$ FPL & $\$ 4,000$ \\
$300-400 \%$ FPL & $\$ 3,000$ \\
\hline
\end{tabular}

Table 2: Summary Statistics

\begin{tabular}{lcccc}
\hline \hline & \multicolumn{2}{c}{$\begin{array}{c}\text { Non-participating } \\
\text { AQMDs }\end{array}$} & \multicolumn{2}{c}{ Participating AQMDs } \\
& \multicolumn{2}{c}{ (South Coast/San Joaquin) } \\
& non-DAC & DAC & non-DAC & DAC \\
\hline EV Sales, Pre & 60,789 & 26,993 & 31,524 & 39,424 \\
EV Sales, Post & 85,677 & 29,840 & 45,316 & 63,692 \\
EV Sales Per Capita (per 000 pop), Pre & 5.729 & 3.971 & 7.916 & 2.345 \\
EV Sales Per Capita (per 000 pop), Post & 8.075 & 4.390 & 11.38 & 3.789 \\
Count of EFMP EV trans., Pre & 0 & 0 & 0 & 0 \\
Count of EFMP EV trans., Post & 0 & 0 & 29 & 1330 \\
EFMP Frac. of Sales, Pre & 0 & 0 & 0 & 0 \\
EFMP Frac. of Sales, Post & 0 & 0 & 0.000640 & 0.0209 \\
Mean Sales Price (\$), Pre & $37,391.4$ & $33,964.5$ & $38,516.7$ & $34,470.5$ \\
Mean Sales Price (\$), Post & $39,110.1$ & $35,997.8$ & $41,596.1$ & $36,544.0$ \\
Mean Subsidy (\$), Pre & 0 & 0 & 0 & 0 \\
Mean Subsidy (\$), Post & 0 & 0 & 2.008 & 191.2 \\
Frac. zips in SCAQMD & 0 & 0 & 0.860 & 0.684 \\
Population (MMs) & 10.61 & 6.798 & 3.983 & 16.81 \\
\hline \hline
\end{tabular}


Table 3: Zip Code Demographics

\begin{tabular}{lccccc}
\hline \hline & & \multicolumn{3}{c}{ Population Weighted } & \multicolumn{3}{c}{ Sales Weighted } \\
\cline { 3 - 6 } & All CA & Non-pilot DACs & Pilot DACs & EV Sales (2014-2018) & EFMP Sales \\
\hline Mean Income (\$000) & 93.1 & 85.9 & 76.2 & 128.0 & 75.9 \\
& $(38.6)$ & $(29.3)$ & $(24.5)$ & $(52.1)$ & $(22.0)$ \\
Frac. HH < FPL (\%) & 35.0 & 38.0 & 42.8 & 23.9 & 42.0 \\
& $(16.2)$ & $(13.6)$ & $(15.6)$ & $(13.3)$ & $(14.4)$ \\
Frac. HH < 225\% FPL (\%) & 39.1 & 41.9 & 47.5 & 26.8 & 46.8 \\
& $(17.0)$ & $(14.6)$ & $(15.6)$ & $(14.2)$ & $(14.6)$ \\
Frac. HH <300\% FPL (\%) & 50.8 & 54.2 & 60.5 & 35.8 & 60.2 \\
& $(19.2)$ & $(16.4)$ & $(16.5)$ & $(16.9)$ & $(15.5)$ \\
Frac. HH < 400\% FPL (\%) & 62.5 & 66.0 & 72.2 & 46.3 & 72.1 \\
& $(19.2)$ & $(16.1)$ & $(15.6)$ & $(18.4)$ & $(14.3)$ \\
Adult HS Grad (\%) & 79.8 & 78.0 & 71.9 & 88.7 & 72.9 \\
& $(14.3)$ & $(11.5)$ & $(14.5)$ & $(9.7)$ & $(13.2)$ \\
Fraction Hispanic (\%) & 37.7 & 38.6 & 51.9 & 23.1 & 48.6 \\
Fraction African American (\%) & $(23.7)$ & $(20.6)$ & $(22.1)$ & $(17.5)$ & $(21.2)$ \\
& $(8.8$ & 8.5 & 7.0 & 4.2 & 6.2 \\
Fraction Asian American (\%) & 13.2 & $(8.5)$ & $(9.6)$ & $(6.0)$ & $(8.2)$ \\
Unemployment Rate (\%) & $(13.5)$ & $(13.8)$ & $(12.6)$ & 18.1 & 16.8 \\
Max CES score in Zip & 11.2 & 12.4 & 12.5 & $(15.8)$ & $(16.4)$ \\
& $(3.8)$ & $(3.8)$ & $(3.6)$ & 8.9 & 12.7 \\
\hline \hline
\end{tabular}


Table 4: Pass-Through and EFMP Incentives

Panel A: Impact on retail price, net of subsidy

\begin{tabular}{|c|c|c|c|c|c|c|}
\hline & $\begin{array}{c}(1) \\
\text { DinD }\end{array}$ & $\begin{array}{c}\text { OLS } \\
(2) \\
\text { Matched DinD }\end{array}$ & $\begin{array}{c}\text { (3) } \\
\text { Triple Diff }\end{array}$ & $\begin{array}{c}(4) \\
\text { DinD }\end{array}$ & $\begin{array}{c}\text { IV } \\
\text { (5) } \\
\text { Matched DinD }\end{array}$ & $\begin{array}{c}(6) \\
\text { Triple Diff }\end{array}$ \\
\hline \% EFMP Transactions & $\begin{array}{c}-3715.4^{* * *} \\
(1364.3)\end{array}$ & $\begin{array}{l}-2953.6^{*} \\
(1593.6)\end{array}$ & $\begin{array}{c}-3521.2^{* * *} \\
(1348.1)\end{array}$ & $\begin{array}{c}-5324.2^{* * *} \\
(1167.2)\end{array}$ & $\begin{array}{c}-4673.4^{* * *} \\
(1215.6)\end{array}$ & $\begin{array}{c}-5313.0^{* * *} \\
(1160.8)\end{array}$ \\
\hline Observations & 12495 & 16415 & 25139 & 12468 & 16415 & 25112 \\
\hline $\begin{array}{l}\text { R-Squared } \\
\text { First-stage F-stat }\end{array}$ & 0.11 & 0.098 & 0.14 & 950 & 683 & 955 \\
\hline Hansen Test $p$-value & & & & 0.74 & 0.19 & 0.76 \\
\hline
\end{tabular}

Panel B: Pass-through to retail price, net of subsidies

\begin{tabular}{|c|c|c|c|c|c|c|}
\hline & $\begin{array}{c}(1) \\
\text { DinD }\end{array}$ & $\begin{array}{c}\text { OLS } \\
(2) \\
\text { Matched DinD }\end{array}$ & $\begin{array}{c}\text { (3) } \\
\text { Triple Diff }\end{array}$ & $\begin{array}{c}(4) \\
\text { DinD }\end{array}$ & $\begin{array}{c}\text { IV } \\
(5) \\
\text { Matched DinD }\end{array}$ & $\begin{array}{l}\text { (6) } \\
\text { Triple Diff }\end{array}$ \\
\hline Avg. PU Subsidy & $\begin{array}{c}-0.76^{* * *} \\
(0.28)\end{array}$ & $\begin{array}{l}-0.57^{*} \\
(0.32)\end{array}$ & $\begin{array}{c}-0.72^{* * *} \\
(0.28)\end{array}$ & $\begin{array}{c}-1.08^{* * *} \\
(0.24)\end{array}$ & $\begin{array}{c}-0.94^{* * *} \\
(0.24)\end{array}$ & $\begin{array}{c}-1.08^{* * *} \\
(0.24)\end{array}$ \\
\hline Observations & 12495 & 16415 & 25139 & 12468 & 16415 & 25112 \\
\hline $\begin{array}{l}\text { R-Squared } \\
\text { First-stage F-stat } \\
\text { Hansen Test p-value }\end{array}$ & 0.11 & 0.097 & 0.13 & $\begin{array}{l}92.8 \\
0.70\end{array}$ & $\begin{array}{l}6 \dot{6} .2 \\
0.21\end{array}$ & $\begin{array}{l}93.3 \\
0.71\end{array}$ \\
\hline
\end{tabular}

Dependent variable is average residual price in a zip*quarter, after conditioning on Make*Model ${ }^{*}$ Model- $^{*}$ year*Year of Sale fixed effects. Standard errors are clustered by zip code. Columns 1, 2 and 3 are OLS regressions for the unmatched Differences-in-Differences, the matched Difference-in-Differences and the Tripledifferenced specifications, respectively. Columns 4, 5 and 6 present IV estimates of columns 1 through 3 using our preferred instrument. 
Table 5: EV Sales and EFMP Incentives

Panel A: Impact of EFMP subsidy

\begin{tabular}{|c|c|c|c|c|c|c|}
\hline & $\begin{array}{c}(1) \\
\text { DinD }\end{array}$ & $\begin{array}{c}\text { OLS } \\
\text { (2) } \\
\text { Matched DinD }\end{array}$ & $\begin{array}{c}(3) \\
\text { Triple Diff }\end{array}$ & $\begin{array}{c}(4) \\
\text { DinD }\end{array}$ & $\begin{array}{c}\text { IV } \\
\text { Matched DinD }\end{array}$ & $\begin{array}{c}(6) \\
\text { Triple Diff }\end{array}$ \\
\hline \% EFMP Transactions & $\begin{array}{l}0.23^{* * *} \\
(0.058)\end{array}$ & $\begin{array}{l}0.29^{* * *} \\
(0.063)\end{array}$ & $\begin{array}{c}0.24^{* * *} \\
(0.057)\end{array}$ & $\begin{array}{l}0.81^{* * *} \\
(0.076)\end{array}$ & $\begin{array}{c}0.86^{* * *} \\
(0.093)\end{array}$ & $\begin{array}{l}0.82^{* * *} \\
(0.077)\end{array}$ \\
\hline Observations & 15801 & 19458 & 34477 & 15621 & 19278 & 34297 \\
\hline $\begin{array}{l}\text { R-Squared } \\
\text { First-stage F-stat }\end{array}$ & 0.87 & 0.87 & 0.90 & 1059 & 909 & 1066 \\
\hline Hansen Test p-value & & & & 0.27 & 0.20 & 0.26 \\
\hline
\end{tabular}

Panel B: Impact of $\$ 1,000$ incentive

\begin{tabular}{|c|c|c|c|c|c|c|}
\hline & $\begin{array}{c}(1) \\
\text { DinD }\end{array}$ & $\begin{array}{c}\text { OLS } \\
(2) \\
\text { Matched DinD }\end{array}$ & $\begin{array}{c}\text { (3) } \\
\text { Triple Diff }\end{array}$ & $\begin{array}{c}(4) \\
\operatorname{DinD}\end{array}$ & $\begin{array}{c}\text { IV } \\
\text { Matched DinD }\end{array}$ & $\begin{array}{c}\text { (6) } \\
\text { Triple Diff }\end{array}$ \\
\hline Avg. PU Subsidy & $\begin{array}{c}0.048^{* * *} \\
(0.012)\end{array}$ & $\begin{array}{c}0.060^{* * *} \\
(0.013)\end{array}$ & $\begin{array}{c}0.050^{* * *} \\
(0.012)\end{array}$ & $\begin{array}{l}0.17^{* * *} \\
(0.015)\end{array}$ & $\begin{array}{l}0.18^{* * *} \\
(0.019)\end{array}$ & $\begin{array}{l}0.17^{* * *} \\
(0.015)\end{array}$ \\
\hline $\begin{array}{l}\text { Observations } \\
\text { R-Squared }\end{array}$ & $\begin{array}{c}15801 \\
0.87\end{array}$ & $\begin{array}{c}19458 \\
0.87\end{array}$ & $\begin{array}{c}34477 \\
0.90\end{array}$ & 15621 & 19278 & 34297 \\
\hline $\begin{array}{l}\text { First-stage F-stat } \\
\text { Hansen Test p-value }\end{array}$ & & & & $\begin{array}{c}103.1 \\
0.29\end{array}$ & $\begin{array}{l}85.8 \\
0.22\end{array}$ & $\begin{array}{c}103.8 \\
0.27\end{array}$ \\
\hline
\end{tabular}

Dependent variable is log of sales in a zip*quarter. Standard errors are clustered by zip code. Columns 1,2 and 3 are OLS regressions for the unmatched Differences-in-Differences, the matched Difference-inDifferences and the Triple-differenced specifications, respectively. Columns 4, 5 and 6 present IV estimates of columns 1 through 3 using our preferred instrument.

Table 6: Demand Elasticity of Electric Vehicles

\begin{tabular}{lcccccc}
\hline & $\begin{array}{c}\text { Difference-in-Difference } \\
(1)\end{array}$ & $(2)$ & $\begin{array}{c}\text { Matched Diff-in-diff } \\
(3)\end{array}$ & $\begin{array}{c}\text { Triple Differenced } \\
(4)\end{array}$ & $(5)$ & $(6)$ \\
\hline \% Premium & $-3.21^{* * *}$ & $-3.28^{* * *}$ & $-3.19^{* * *}$ & $-3.26^{* * *}$ & $-3.24^{* * *}$ & $-3.31^{* * *}$ \\
& $(0.94)$ & $(0.95)$ & $(1.18)$ & $(1.21)$ & $(0.94)$ & $(0.95)$ \\
\hline Observations & 12468 & 12468 & 15710 & 15710 & 25112 & 25112 \\
\hline Dependent variable is log of sales in a zip* quarter, regressed upon the premium or \\
discount in the zip-quarter relative to mean sales price. Standard errors are clus- \\
tered by zip code. Columns 1, 3 and 5 present the IV results using the Differences-in- \\
Differences, the matched Difference-in-Differences and the Triple-differenced specifi- \\
cations, respectively, using the fraction EFMP sales instrument described in the text. \\
Columns 2, 4 and 6 recreate the IV results for the three specifications using the average \\
subsidy instrument described in the text.
\end{tabular}


Table 7: Results by Air District

\begin{tabular}{|c|c|c|c|c|c|c|c|c|}
\hline & \multicolumn{4}{|c|}{ DepVar = Price } & \multicolumn{4}{|c|}{ Dep Var $=\log Q$} \\
\hline & $(1)$ & (2) & (3) & (4) & $(5)$ & $(6)$ & (7) & $(8)$ \\
\hline & OLS & & & IV & OLS & & O'LS & IV \\
\hline$\%$ EFMP * South Coast & $\begin{array}{l}-3063.9 \\
(2330.7)\end{array}$ & $\begin{array}{c}-3329.7^{*} \\
(1834.4)\end{array}$ & & & $\begin{array}{l}0.028 \\
(0.13)\end{array}$ & $\begin{array}{c}0.98^{* * *} \\
(0.15)\end{array}$ & & \\
\hline$\%$ EFMP * San Joaquin & $-3572.6^{* *}$ & $-5550.6^{* * *}$ & & & $0.36^{* * *}$ & $0.88^{* * *}$ & & \\
\hline Avg. PU Subs. * South Coast & (1688.6) & $(1449.9)$ & $\begin{array}{l}-0.60 \\
(0.49)\end{array}$ & $\begin{array}{c}-0.71^{*} \\
(0.39)\end{array}$ & $(0.064)$ & $(0.092)$ & $\begin{array}{l}0.0059 \\
(0.027)\end{array}$ & $\begin{array}{l}0.20^{* * *} \\
(0.031)\end{array}$ \\
\hline Avg. PU Subs. * San Joaquin & & & $\begin{array}{c}-0.73^{* *} \\
(0.34)\end{array}$ & $\begin{array}{c}-1.11^{* * *} \\
(0.29)\end{array}$ & & & $\begin{array}{c}0.076^{* * *} \\
(0.013)\end{array}$ & $\begin{array}{l}0.18^{* * *} \\
(0.019)\end{array}$ \\
\hline Observations & 25139 & 25112 & 25139 & 25112 & 34477 & 34297 & 34477 & 34297 \\
\hline R-Squared & 0.14 & & 0.14 & & 0.90 & & 0.90 & \\
\hline First-stage F-stat & & 47.7 & & 45.9 & & 57.0 & & 54.3 \\
\hline Hansen Test $p$-value & & 0.32 & & 0.29 & & 0.68 & & 0.67 \\
\hline
\end{tabular}

The dependent variables in columns 1 through 4 and columns 5 through 8 are average residual prices and log quantities respectively. dd-numbered columns report the OLS results. Even-numbered columns report IV results using the preferred instruments. All columns are based on the triple-differenced specification. Standard errors are clustered at the zip code.

Table 8: Estimated CA Subsidy Required to Meet 1.5 Million ZEVs by 2025 Goal

\begin{tabular}{|c|c|c|c|c|c|c|}
\hline & \multicolumn{6}{|c|}{ Baseline Growth Rate in EVs (2018-2025) } \\
\hline & $10 \%$ & \multicolumn{2}{|r|}{$12 \%$} & $14 \%$ & \multicolumn{2}{|r|}{$16 \%$} \\
\hline \multicolumn{7}{|l|}{ Elasticity $=2.0$} \\
\hline Implied required change in Buy Price & N/A & $\$$ & $(20,902)$ & $(14,038)$ & $\$$ & $(9,009)$ \\
\hline Cumulative Subsidy Bill (\$ Billions) & N/A & $\$$ & 26.9 & 18.0 & $\$$ & 11.6 \\
\hline \multicolumn{7}{|l|}{ Elasticity $=3.3$} \\
\hline Implied required change in Buy Price $\$$ & $(19,814)$ & $\$$ & $(13,485)$ & $(9,057)$ & $\$$ & $(5,812)$ \\
\hline Cumulative Subsidy Bill (\$ Billions) \$ & 26.6 & $\$$ & 18.0 & $\$ \quad 12.0$ & $\$$ & 7.7 \\
\hline \multicolumn{7}{|c|}{$\begin{array}{l}\text { Estimates assume that } 10 \% \text { of the EV fleet is retired or exported each year starting in } 2020 \text { and a weighted-average } \\
\text { (over new and used) EV price of approxiately } \$ 26,000 \text {. There are } 333,000 \text { EVs assumed to be in the fleet at the } \\
\text { beginning of } 2018 \text {. By our estimates, the zero-subsidy growth rate of California EVs in } 2015,2016 \text { and } 2017 \text { were } \\
32.3,24.3 \text { percent and } 20.8 \text { percent respectively. "N/A" reflects subsidies that exceed } 100 \text { percent of the assumed } \\
\text { value of the car. }\end{array}$} \\
\hline
\end{tabular}




\section{A Appendix}

\section{A.1 Supplementary Figures and Tables}

Figure A1: EFMP Eligibility Flowchart
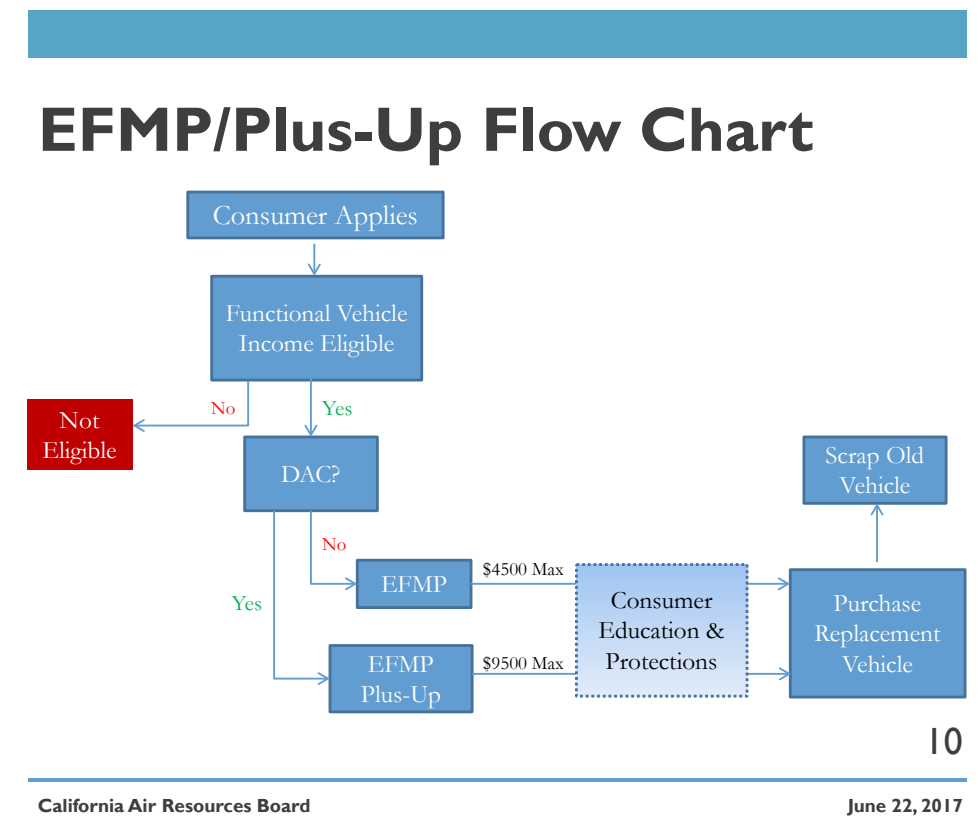

Source: https:/ /www.arb.ca.gov/board/books/2017/062217/17-6-1pres.pdf 
Figure A2: CalEnviroScreen Components

\begin{tabular}{|c|c|c|c|c|c|}
\hline & $\begin{array}{l}\text { Pollution } \\
\text { Burden }\end{array}$ & & \multicolumn{2}{|c|}{ Population Characteristics } & \\
\hline 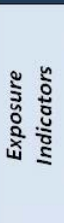 & $\begin{array}{l}\text { Ozone Concentrations } \\
\text { PM2.5 Concentrations } \\
\text { Diesel PM Emissions } \\
\text { Drinking Water Contaminants } \\
\text { Pesticide Use } \\
\text { Toxic Releases from Facilities } \\
\text { Traffic Density }\end{array}$ & & 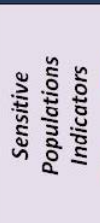 & $\begin{array}{l}\text { Children and Elderly } \\
\text { Low Birth-Weight } \\
\text { Births } \\
\text { Asthma Emergency } \\
\text { Departmental Visits }\end{array}$ & CalFnviroScreen \\
\hline 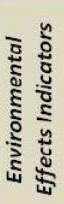 & $\begin{array}{l}\text { Cleanup Sites }(1 / 2) \\
\text { Groundwater Threats (1/2) } \\
\text { Hazardous Waste }(1 / 2) \\
\text { Impaired Water Bodies }(1 / 2) \\
\text { Solid Waste Sites and } \\
\quad \text { Facilities }(1 / 2)\end{array}$ & $\hat{n}$ & 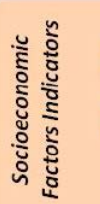 & $\begin{array}{l}\text { Educational Attainment } \\
\text { Linguistic Isolation } \\
\text { Poverty } \\
\text { Unemployment }\end{array}$ & - $\quad$ Score \\
\hline
\end{tabular}

Figure A3: DACs and AQMD borders, Major Metro Areas

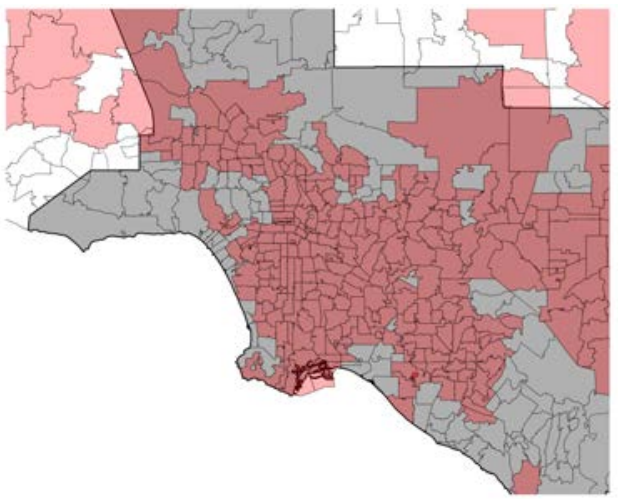

(a) Los Angeles

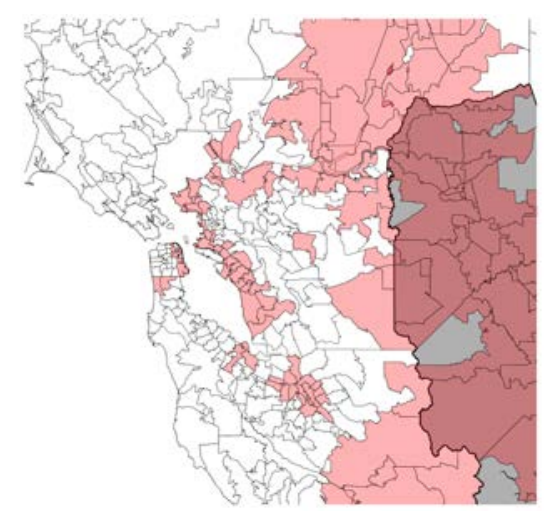

(c) San Francisco

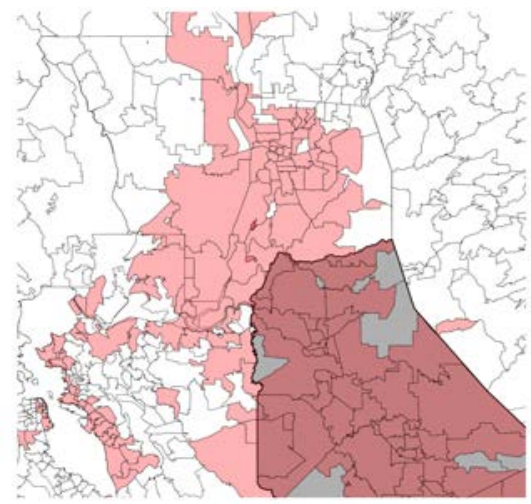

(b) Sacramento

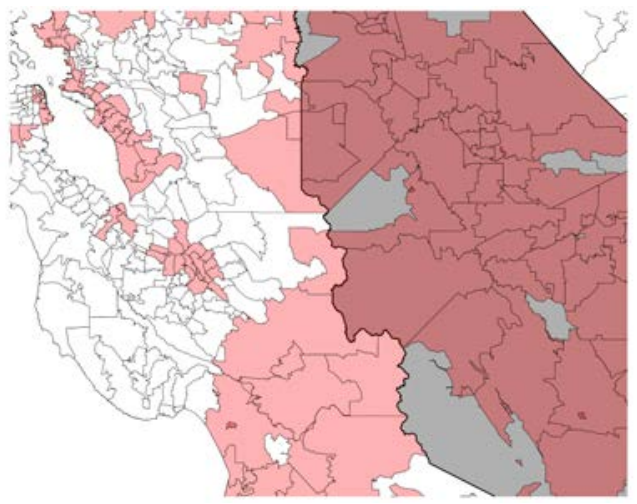

(d) San Jose 
Figure A4: Population and Subsidies by Max-CES Score

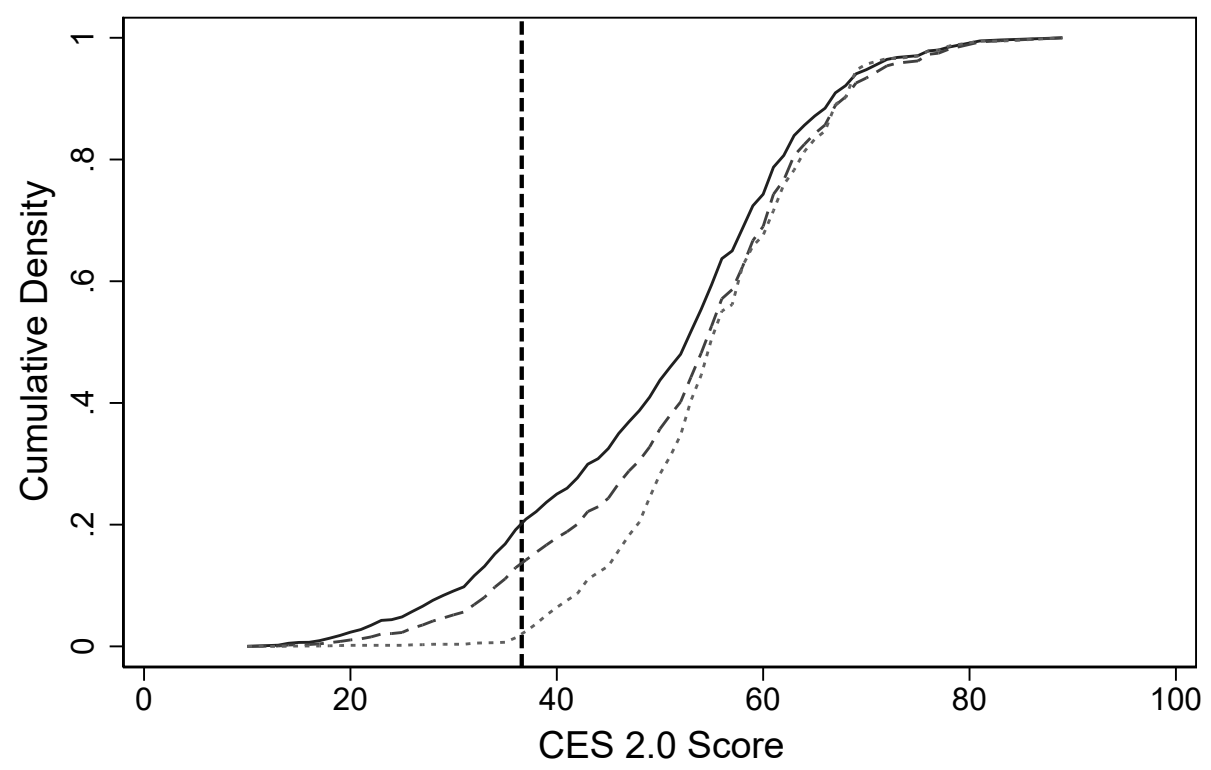

Population

- - - - Population below 400\% FPL

Value of EFMP Subsidies

Note: The graph plots the cumulative distributions of population, population below 400\% of FPL, and value of EFMP subsidies within the Pilot Region AQMDs. The dashed vertical line corresponds to the disadvantaged community CES score cutoff of 36.6.

Figure A5: Trends in Prices and Quantities, Disadvantaged Communities in and out of Pilot Regions for samples matched on pre-trends
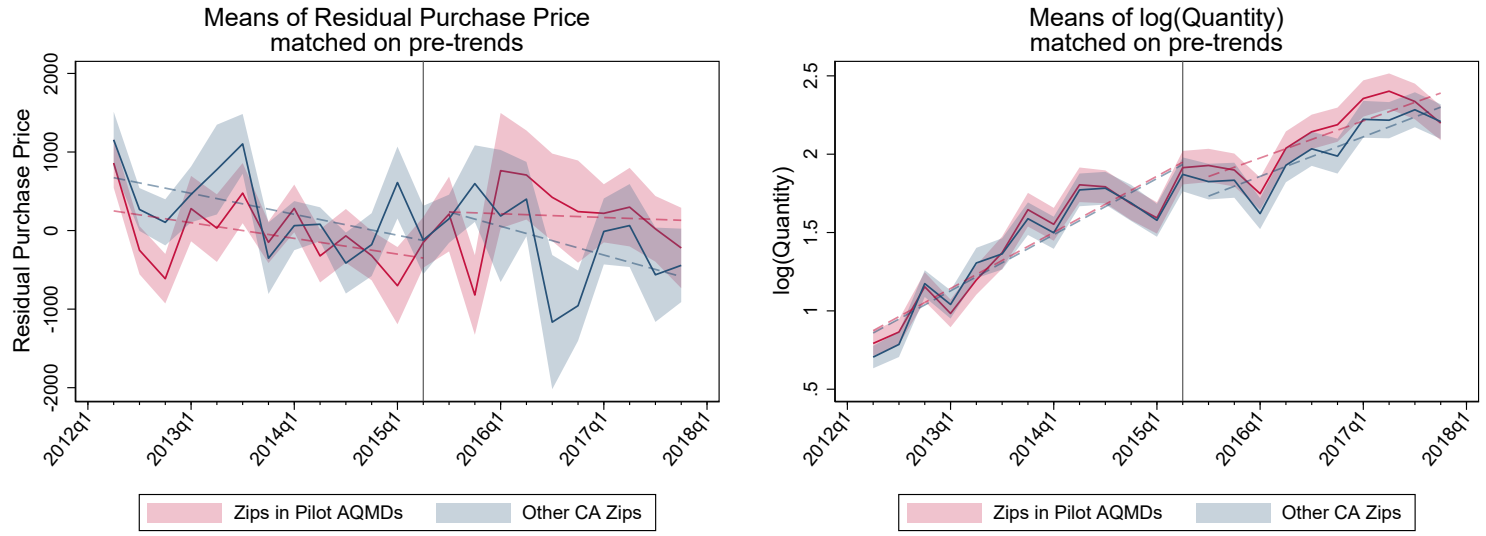

Note: Red and blue lines correspond to the unweighted average prices and log quantities in disadvantaged communities in and out of the pilot regions, respectively. Vertical line corresponds to the start quarter for the EFMP program. Price graphs plot the mean residual prices for disadvantaged communities in an out of the pilot regions after conditioning on make-model-modelyear fixed effects. 


\section{A.2 Instrumental Variables}

Our primary variables, EFMP-share of total transactions and the average subsidy across all transactions, are normalized by the total quantity of electric vehicles in a zip*quarter. This creates a structural endogeneity between the error term and the dependent variable, most clear in regressions where the dependent variable is log of total transactions. When constructing an instrument, the relevant exclusion restriction is that the error term is uncorrelated with the instrument. A necessary condition for the exclusion restriction to hold is that contemporaneous quantities in a zip code does not enter the construction of the instrument, either directly or indirectly.

Formally, denoting the number of post-period quarters as $T$, the quarter in which the EFMP program becomes active as $t *$ and the average number of transactions in zip $z$ in quarter $t$ as $Q_{z t}=\sum_{i} \mathbf{1}(z i p=z$, time $=t)$, we construct our preferred instrument for EFMP-share as:

$$
\text { PreferredI } V_{z t}=\frac{\sum_{i} \mathbf{1}\left(\text { Subsidy }_{i z t}>0, z i p=z, \text { time }=t\right)}{\frac{\sum_{r \neq t, r \geq t *} Q_{z r}}{T-1} \frac{\sum_{x \neq z} Q_{x t}}{\sum_{r \geq t *} \sum_{x \neq z} Q_{x r} / T-1}}
$$

The numerator of the instrument is identical to the numerator of EFMP-share. On the other hand, the first term in the denominator is the average number of total transactions in zip $z$ in the post period, leaving out the current period. This captures largely cross-sectional variation across zip codes reflecting how many EVs are typically purchased in a location. The second term is the ratio of contemporaneous sales in all other zip codes in the district, to the average sales in all quarters except this one. This largely captures time-series variation with regards to EV sales in the air district. Note that this instrument excludes contemporaneous quantities in a zip code at time t. Absent autocorrelation or spatial correlation of preferences, which would lead contemporaneous quantities in a zip code to be either correlated with the former or latter, respectively.

We also construct three alternative instruments. The first two relax the assumptions of spatial correlation and autocorrelation of preferences, respectively. Formally,

$$
\begin{aligned}
& \text { AlternativeIV } 1_{z t}=\frac{\sum_{i} \mathbf{1}\left(\text { Subsidy }_{i z t}>0, z i p=z \text {, time }=t\right)}{\frac{\sum_{r \neq t, r \geq t *} Q_{z r}}{T-1}} \\
& \text { AlternativeIV }_{z t}=\frac{\sum_{i} \mathbf{1}\left(\text { Subsidy }_{i z t}>0, z i p=z, \text { time }=t\right)}{\sum_{x \neq z} Q_{x t}}
\end{aligned}
$$

Alternative IV 1 is identical to our preferred instrument, but excludes the time-series variation provided by average EV sales of other zip in district. If we worry that spatial correlation of sales invalidates our preferred instrument, alternative IV 1 does not rely on contemporaneous 
sales at all. In a similar fashion, alternative IV 2 excludes the cross-sectional variation provided by the average sales in the zip leaving out contemporaneous sales, allowing for autocorrelation in sales.

Finally, the third alternative instrument is a traditional shift-share instrument, interacting cross-sectional variation in the fraction of households in the zip code below $225 \%$ of the federal poverty line with time-series variation in either state-wide EFMP share or state-wide mean EFMP subsidy.

\section{A.3 Backing out and elasticity estimate}

The coefficients estimated from the quantity regressions reflect the response of the log of all sales in a zip-quarter to the EFMP program. However, from a policy perspective, we may be interested in two expressions of interest, the percentage change in EV sales from offering a $\$ 1000$ subsidy and the elasticity of demand, both specifically in relation to the population of EFMP-eligible individuals.

Letting $\eta$ denote the fraction of EFMP-eligible buyers in a zip-quarter, $N$ the number of buyers, $P_{0}$ the "buy price" for non-participants and $P_{0}-\beta S$ as the "buy price" for participants, where $S$ is the total value of the subsidy and $\beta$ is the fraction of the subsidy captured by buyers, we can express the log of quantity as a function of the quantity for a representative eligible consumer, $Q_{E}$ and an ineligible consumer, $Q_{I}$ as follows:

$$
\log \left(Q_{z t}\right)=\log \left(N \eta Q_{E}\left(P_{0}-\beta S\right)+N(1-\eta) Q_{I}\left(P_{0}\right)\right)
$$

Our specification regresses the log of quantity against the average subsidy in a quarter-zip $(\lambda S)$. Consequently, the estimated coefficient, $\phi$, is an estimate of $\frac{d \log Q}{d \lambda S}$. Noting that $\frac{d S}{d \lambda S}=1 / \lambda$, taking the derivative of $\log \left(Q_{z t}\right)$ with respect to $S$ gives:

$$
\lambda \phi=\frac{-\eta \beta N \frac{d Q_{E}}{d P}}{N \eta Q_{E}+(1-\eta) Q_{I}} .
$$

Noting that $\lambda$ is the fraction of transactions that were part of the EFMP program, $\frac{\eta Q_{E}}{\eta Q_{E}+(1-\eta) Q_{I}}$, we can rewrite (18) as the response of the log sales of the EFMP-eligible consumers to a unit change in subsidy $S$ :

$$
\frac{d \log \left(N \eta Q_{E}\right)}{d S}=\frac{N \eta \frac{d Q_{E}}{d P} \beta}{N \eta Q_{E}\left(P_{0}-\beta S\right)}=\phi .
$$

Rearranging the latter quality, we can characterize the elasticity of demand of EFMP-eligible buyers as:

$$
\varepsilon_{Q_{E}}^{P}=\frac{\phi}{\beta} P_{E}
$$




\section{A.4 Estimates of the Baseline EV Growth Rate}

Table A1: EV Growth Rates: Subsidy and Net-of-Subsidy Estimates

\begin{tabular}{ccrrr}
\hline Year & $\begin{array}{c}\text { Cumulative } \\
\text { EVs }\end{array}$ & $\begin{array}{c}\text { Raw Growth } \\
\text { Rate }\end{array}$ & $\begin{array}{c}\text { Subsidy Sales } \\
\text { Estimate }\end{array}$ & $\begin{array}{c}\text { Net-of- } \\
\text { Subsidy } \\
\text { ("Base") } \\
\text { Growth Rate }\end{array}$ \\
\hline 2013 & 42,545 & & 22,562 & \\
2014 & 102,030 & $82.3 \%$ & 31,545 & $74.1 \%$ \\
2015 & 164,247 & $46.7 \%$ & 32,994 & $32.3 \%$ \\
2016 & 239,412 & $37.2 \%$ & 39,860 & $24.3 \%$ \\
2017 & 333,114 & $32.7 \%$ & 49,690 & $20.8 \%$ \\
\hline
\end{tabular}

Note: Net-of-subsidy sales calculated assuming a subsidy elasticity of -3.1,

$\$ 10,000$ in subsidies. 